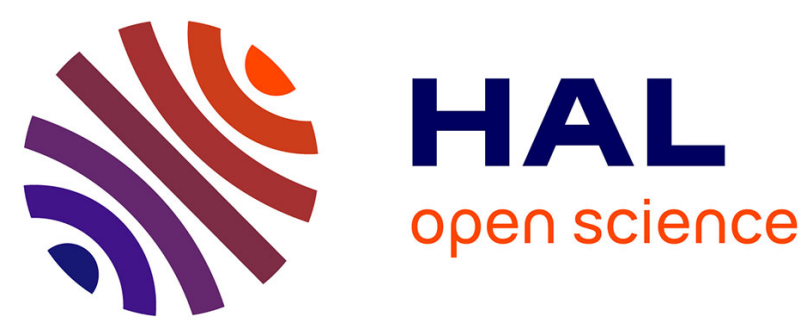

\title{
Versatile and robust synthesis process for the fine control of the chemical composition and core-crystallinity of spherical core-shell Au@Ag nanoparticles
}

Suyeon Lee, Hervé Portalès, Michael Walls, Patricia Beaunier, Nicolas

Goubet, Benoit Tremblay, Jérémie Margueritat, Lucien Saviot, Alexa Courty

\section{To cite this version:}

Suyeon Lee, Hervé Portalès, Michael Walls, Patricia Beaunier, Nicolas Goubet, et al.. Versatile and robust synthesis process for the fine control of the chemical composition and core-crystallinity of spherical core-shell Au@Ag nanoparticles. Nanotechnology, 2021, 32, pp.095604. 10.1088/13616528/abc450 . hal-02994816

\section{HAL Id: hal-02994816 https://hal.science/hal-02994816}

Submitted on 8 Nov 2020

HAL is a multi-disciplinary open access archive for the deposit and dissemination of scientific research documents, whether they are published or not. The documents may come from teaching and research institutions in France or abroad, or from public or private research centers.
L'archive ouverte pluridisciplinaire HAL, est destinée au dépôt et à la diffusion de documents scientifiques de niveau recherche, publiés ou non, émanant des établissements d'enseignement et de recherche français ou étrangers, des laboratoires publics ou privés. 


\title{
Versatile and robust synthesis process for the fine control of the chemical composition and core-crystallinity of spherical core-shell Au@Ag nanoparticles
}

\author{
Suyeon Lee, ${ }^{1}$ Hervé Portalès, ${ }^{1}$ Michael Walls, ${ }^{2}$ Patricia Beaunier, ${ }^{3}$ Nicolas Goubet, ${ }^{1}$ Benoit \\ Tremblay ${ }^{1}$, Jérémie Margueritat, ${ }^{4}$ Lucien Saviot ${ }^{5}$ and Alexa Courty ${ }^{1} *$ \\ 1-Sorbonne Université, MONARIS, CNRS-UMR 8233, 4 Place Jussieu, 75005 Paris, France. \\ 2-Laboratoire de Physique des Solides, Université Paris-Saclay, 91405 Orsay, France \\ 3-Sorbonne Université, Laboratoire de Réactivité de Surface, UMR 7197-CNRS, 4 Place \\ Jussieu, 75005 Paris Cedex 05, France \\ 4- Institut Lumière Matière, UMR 5306 CNRS-UCBL, 10 rue Ada Byron, 69622 \\ Villeurbanne Cedex, France \\ 5- Laboratoire Interdisciplinaire Carnot de Bourgogne, UMR 6303 CNRS-Université \\ Bourgogne Franche-Comté, 9 avenue Alain Savary, BP 47870, 21078 Dijon Cedex, France \\ *Corresponding author: alexa.courty@sorbonne-universite.fr
}

\begin{abstract}
Au nanoparticles (NPs) characterized by distinct surface chemistry (including dodecanethiol or oleylamine as capping agent), different sizes $(\sim 5$ and $\sim 10 \mathrm{~nm})$ and crystallinities (polycrystalline or single crystalline), were chosen as seeds to demonstrate the versatility and robustness of our two-step core-shell Au@Ag NP synthesis process. The central component of this strategy is to solubilize the shell precursor $\left(\mathrm{AgNO}_{3}\right)$ in oleylamine and to induce the growth of the shell on selected seeds under heating. The shell thickness is thus controlled by the temperature, the annealing time, the [shell precursor] / [seed] concentration ratio, seed size and crystallinity. The shell thickness is thus shown to increase with the reactant concentration and to grow faster on polycrystalline seeds. The crystalline structure and chemical composition were characterized by HRTEM, STEM-HAADF, EELS and Raman spectroscopy. The plasmonic response of Au@Ag core-shell NPs as a function of core size and shell thickness was assessed by spectrophotometry and simulated by calculations based on the discrete dipole approximation (DDA) method. Finally, the nearly monodisperse coreshell Au@Ag NPs were shown to form micrometer-scale facetted 3D fcc-ordered superlattices (SLs) after solvent evaporation and deposition on a solid substrate. These SLs are promising candidates for applications as a tunable surface-enhanced Raman scattering (SERS) platform.
\end{abstract}




\section{Introduction}

Nanostructured bimetallic systems, in two-phase or alloyed form, offer a wide range of new properties, potentially extending the already numerous applications of monometallic nanoparticles. Noble metals are of particular interest among bimetallic materials [1-3], because of their specific properties. Silver and gold are the noblest metals (almost full d orbital and high cohesive energy) [4]. Under an electromagnetic field, the electron cloud of such nanoparticles can undergo a coherent collective oscillation movement resulting in the socalled surface plasmon resonance, which is attractive for optical applications [5,6]. They also present specific catalytic properties with a high activity [7]. The synergy between these two metals is highly promising, enhancing their functionality and opening up potential applications in catalysis, spectroscopy and medicine [8-16].

Bimetallic Au@Ag core-shell nanoparticles have received extensive interest for many years due to the possibility of tuning their properties through the size of the core, the thickness of the shell and the structural coupling between the core and the shell. In this way, it becomes possible to modify and control the plasmon resonances for surface-enhanced Raman scattering (SERS) applications, catalysis, and chemical sensing [13,17-22]. The synthesis of alloys or core-shells is facilitated for gold and silver by their similar crystal structure (fcc) and lattice constants ( $a=0.408 \mathrm{~nm}$ for $\mathrm{Au}$ and $0.409 \mathrm{~nm}$ for $\mathrm{Ag}$ ) [19]. The fabrication of $\mathrm{Au} @ \mathrm{Ag}$ core-shell structures results in most cases from the reduction of gold to form a core followed by the reduction of silver ions to coat it [12,15,17,23-27]. Due to the close match of the lattice constants an epitaxial growth of $\mathrm{Ag}$ on the $\mathrm{Au}$ seeds is expected [28]. However, the morphology of the gold seeds can evolve after the deposition of the silver shell depending on experimental conditions such as the type of Au seeds (size, shape, crystalline structure and coating agent) $[18,24,25]$, the precursor of silver ions, the reductant, the capping agent present in the reaction solution $[17,18,25]$, the solvent and the temperature [23]. A wide variety of synthesis protocols have thus been developed in recent years that play on these multiple parameters. Different morphologies of $\mathrm{Au} @ \mathrm{Ag}$ nanoparticles were obtained, including sphere, cube, nanorod, octahedron or decahedron shapes [18,20,21,23,24,29].

This work is based on the development of a versatile and robust synthesis process, which allows the growth of the silver shell on gold seeds under a variety of conditions (seed size, seed crystallinity, and seed surface chemistry). It is based on the use of oleylamine to solubilize and reduce the silver metallic precursor for the shell under annealing for a controlled time at the surface of the Au seed, which is itself synthesized by different pathways 
in an organic medium. The resulting Au@Ag core-shell NPs are of controlled crystallinity and composition; factors that play a fundamental role in their optical and catalytic properties [13,30,31]. Furthermore, they have a narrow size distribution that facilitates their 3D assembly after deposition on a solid substrate for further applications as new SERS platforms with tunable optical properties[32]. SEM, STEM-HAADF, EELS, UV-Visible and lowfrequency Raman spectroscopies (see the section on experimental methods) are used to characterize the crystallinity and chemical composition of the NPs, and their organization. The last two spectroscopic techniques mentioned above allow us to probe the large-scale uniformity of the samples in terms of structure, chemical composition and size.

\section{Results and Discussion}

\subsection{Synthesis of Au@Ag core-shell nanoparticles from different PC core sizes.}

Figures 1(a) and 1(b) show typical TEM images of Au NPs with diameters around 5 and 10 $\mathrm{nm}$ and functionalized by dodecanethiols or oleylamine respectively. After synthesis, the 5 $\mathrm{nm}$ NPs were selected in crystallinity in order to obtain polycrystalline (PC) NPs. They are characterized by a narrow size distribution (both <8\%) (figures 1(a), 1(b), 1(e) and 1(f)) and an average diameter $D_{\text {core }}$ of $5.3 \pm 0.4$ or $10.6 \pm 0.8 \mathrm{~nm}$ depending on the synthesis process used (Table 1). They have a rather spherical shape and are polycrystalline as seen in the darkfield TEM images (figures 1(c) and 1(d)) in which a significant proportion of NPs exhibiting inhomogeneous contrast are present. The different seeds are referred to as $\mathrm{Au}_{5 \mathrm{~nm}}(\mathrm{PC})-\mathrm{C}_{12}$ and $\mathrm{Au}_{10 \mathrm{~nm}}(\mathrm{PC})-\mathrm{C}_{18}$. 

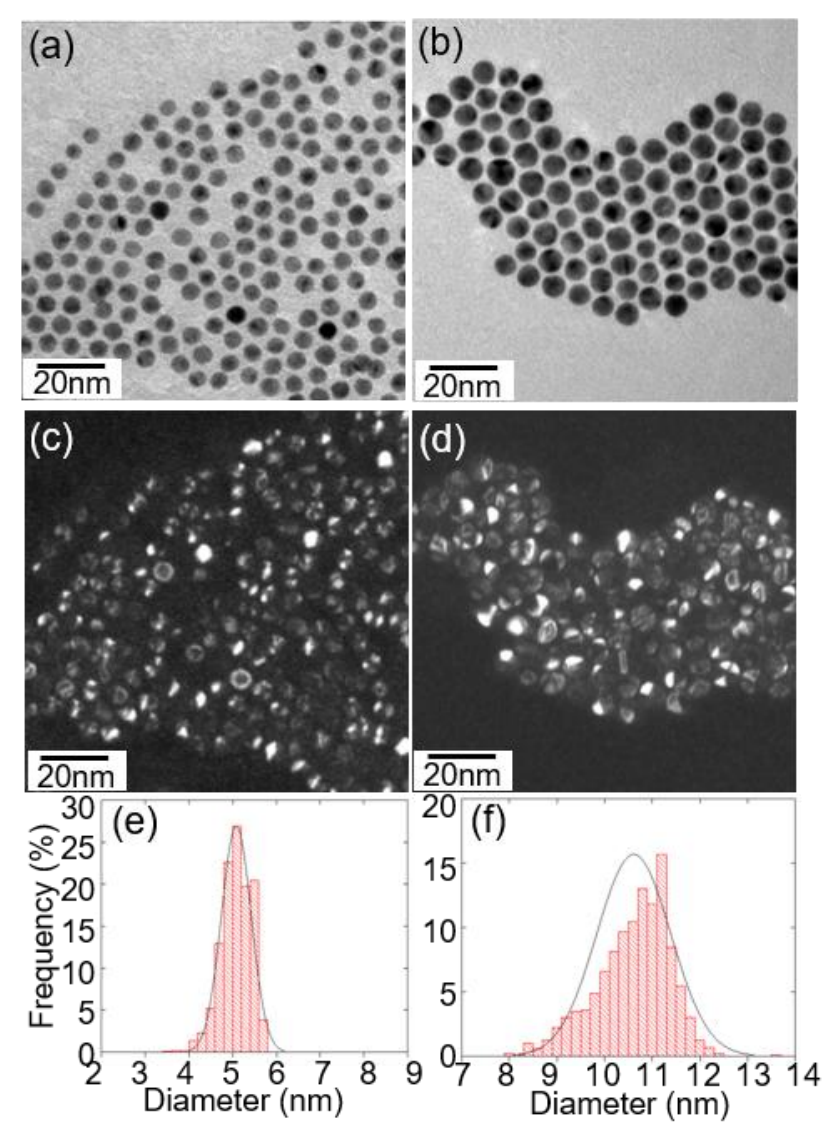

Figure 1. Representative TEM images (a) $\mathrm{Au}_{5 \mathrm{~nm}}(\mathrm{PC})-\mathrm{C}_{12}$, (b) $\mathrm{Au}_{10 \mathrm{~nm}}(\mathrm{PC})-\mathrm{C}_{18}$ seeds and (c, d) the corresponding dark-field TEM images and $(e, f)$ the corresponding size histograms.

The silver shell overgrowth on gold cores was induced by mixing the colloidal solution with a solution of Ag-oleylamine complex under annealing at $90^{\circ} \mathrm{C}$ for 2 or 5 hours depending on the core size (for more details see section 4 experimental methods). The silver growth on the $\mathrm{Au}$ seeds takes place via a surface-catalyzed reaction of $\mathrm{Ag}^{+}$by oleylamine at $90^{\circ} \mathrm{C}$ [33]. A much higher temperature is indeed required to reduce silver nitrate directly in oleylamine and to form nanoparticles [34]. At $90^{\circ} \mathrm{C}$, any nucleation of new silver NPs can thus be avoided. The TEM images of the $\mathrm{Au}_{5 \mathrm{~nm}}(\mathrm{PC}) @ \mathrm{Ag}$ NPs obtained from three different $\mathrm{Au}$ seed concentrations $\left(\mathrm{C}_{\text {seed }}, \mathrm{C}_{\text {seed }} / 2\right.$ and $\left.\mathrm{C}_{\text {seed }} / 4\right)$ and an annealing time fixed at 5 hours are reported in figures 2(a)-(c). As the gold seed concentration decreases, the overall size of $\mathrm{Au}_{5 \mathrm{~nm}}(\mathrm{PC}) @ \mathrm{Ag} \mathrm{NPs}$ increases from $6.3 \pm 0.5$ to $6.6 \pm 0.5$ and $7 \pm 0.6 \mathrm{~nm}$ in diameter and the obtained polydispersity remains low (around 8\%) (figures. 2(d)-(f)) with a Gaussian profile characteristic of a homogeneous growth of silver at the surface of the seeds. The values of the shell thickness e were estimated assuming that the average size of gold cores was $\mathrm{D}_{\text {core }}=$ $5.3 \pm 0.4 \mathrm{~nm}$ and the deposited silver layer was uniform (Table 1 and figure 3 ). 


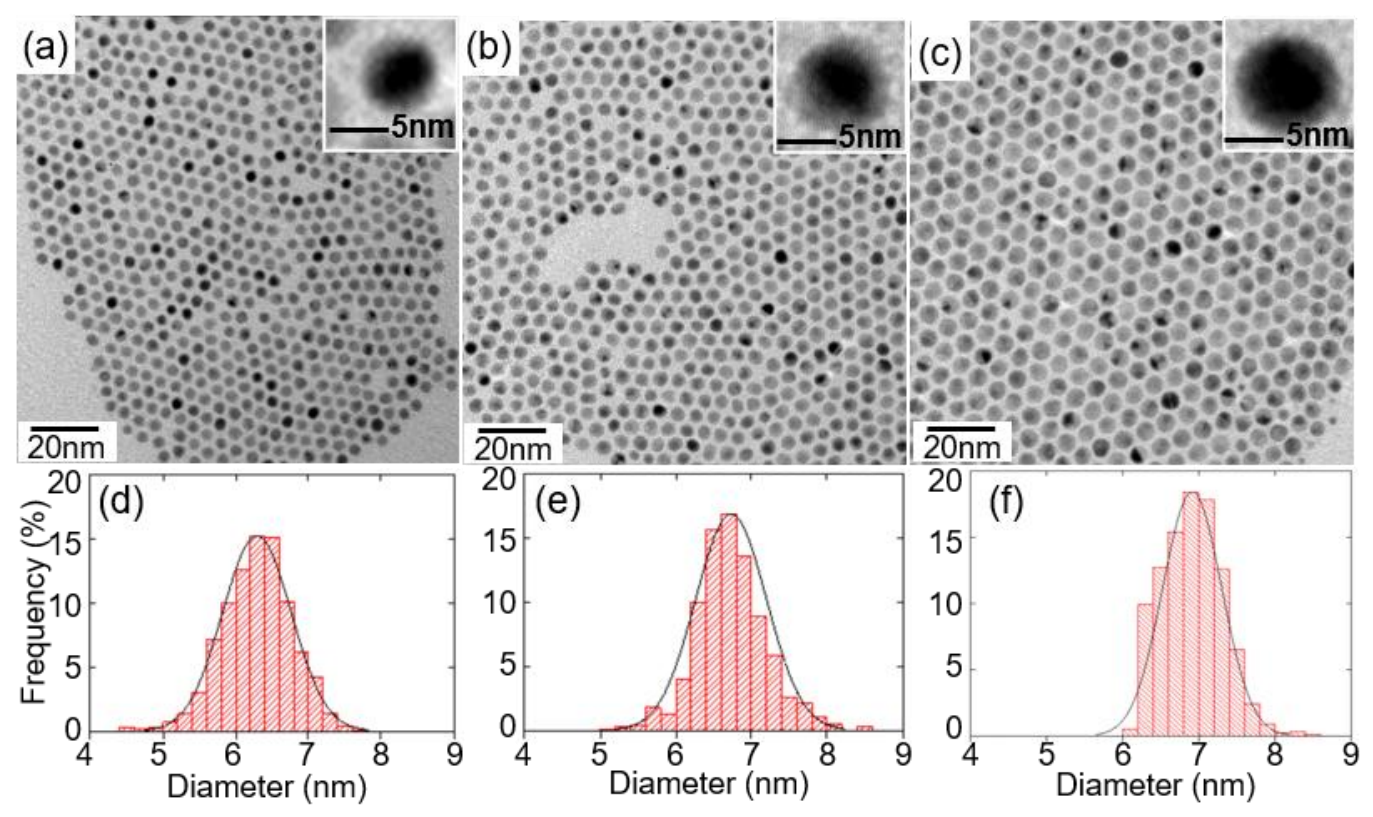

Figure 2. Representative TEM images of $\mathrm{Au}_{5 \mathrm{~nm}}(\mathrm{PC}) @ \mathrm{Ag}$ NPs obtained from different seed concentrations (a) $C_{\text {seed }}$, (b) $C_{\text {seed }} / 2$ and (c) $C_{\text {seed }} / 4$ where $C_{\text {seed }}=1.4 \mu \mathrm{mol} \mathrm{L}-1$ and (d, e, f) the corresponding histogram. In inset: TEM images at higher magnification.

Table 1: Experimental conditions used for the preparation of $\mathrm{Au}_{5 \mathrm{~nm}}(\mathrm{PC}) @ \mathrm{Ag}$ NPs, where e is the silver shell thickness, $\mathrm{V}_{\text {shell }}$ is the silver shell volume $\left(\mathrm{V}_{\text {shell }}=\mathrm{V}_{\mathrm{Au} @ A \mathrm{~g}}-\mathrm{V}_{\text {Au seed }}\right)$ and $\mathrm{R}$ is the [Ag precursor] / [Au seed] concentration ratio.

\begin{tabular}{cccccc}
\hline Samples & $\begin{array}{c}\text { [Au seed }] \\
\left.(\mu \mathrm{mol} \mathrm{L})^{-1}\right)\end{array}$ & $\begin{array}{c}{\left[\mathrm{Ag}^{+}\right]} \\
\left(\mathrm{mmol} \mathrm{L}^{-1}\right)\end{array}$ & $\begin{array}{c}e \\
(\mathrm{~nm})\end{array}$ & $\begin{array}{c}\mathrm{V}_{\text {shell }} \\
\left(\mathrm{nm}^{3}\right)\end{array}$ & $\mathrm{R}$ \\
\hline 1 & 1.4 & 0.825 & 0.5 & 53 & 600 \\
2 & 0.7 & 0.825 & 0.65 & 72 & 1200 \\
3 & 0.35 & 0.825 & 0.85 & 101 & 2400 \\
4 & 1.4 & 1.65 & 0.45 & 47 & 1200 \\
5 & 1.4 & 3.3 & 0.8 & 94 & 2400 \\
\hline
\end{tabular}

Furthermore, the TEM images (insets in figures. 2(a)-(c)) confirm the formation of $\mathrm{Au}_{5 \mathrm{~nm}}(\mathrm{PC}) @ \mathrm{Ag}$ core-shell NPs, as most of the particles have a dark central part and a bright outer part, in agreement with a gold core and a silver shell since gold atoms scatter electrons more strongly than silver. However, strong diffraction contrast affects the visibility of the shell, which is somewhat variable as a function of particle crystallinity and orientation [35]. 
The two elements $\mathrm{Au}$ and $\mathrm{Ag}$ have the same lattice structure (fcc), similar lattice parameters (lattice mismatch less than $0,1 \%$ ) and very close electronegativities (2.5 and 1.9 for $\mathrm{Au}$ and Ag respectively) [19]. These metals thus satisfy the Hume-Rothery rules and are therefore highly miscible [36]. Core-shell Au@Ag nanoparticles are often obtained by depositing silver on $\mathrm{Au}$ seeds. Their conversion to homogeneous alloys is then possible by heating at high temperatures $\left(250-1000^{\circ} \mathrm{C}\right)[37,38]$. Our synthesis process in two steps and at low temperature $\left(90^{\circ} \mathrm{C}\right)$ is thus favorable to the formation of core-shell NPs in agreement with the obtained results. By changing the silver precursor concentration $\mathrm{C}_{\mathrm{Ag}}{ }^{+}$but maintaining similar [Ag precursor] / [Au seed] concentration ratios, we observe an evolution of the silver layer thickness close to the one observed previously by changing the seed concentrations (see Table 1 and figure S1 in supporting information).

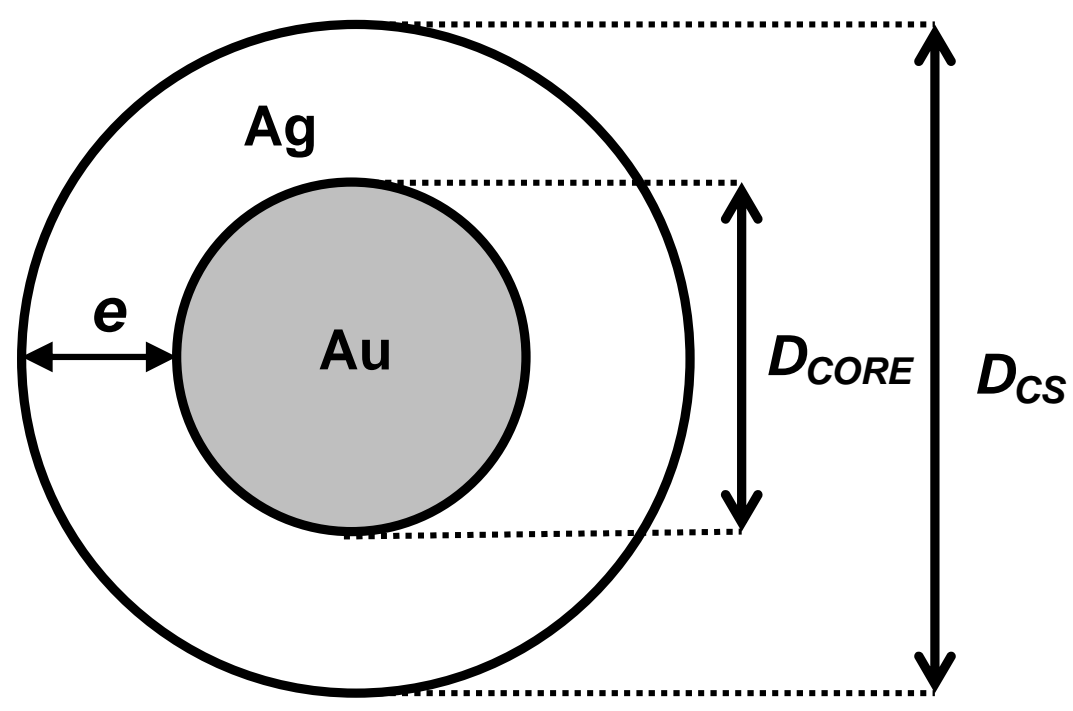

Figure 3. Schematic diagram of a core-shell Au@Ag nanoparticle made of an Au core with diameter $D_{C O R E}$, a total diameter $D_{C S}$ and an Ag thickness $e=\left(D_{C S}-D_{C O R E}\right) / 2$.

Further morphology observations were performed by HAADF-STEM. The HAADF approach can detect the variation in chemical composition of the multi-component sample with an atom-level resolution due to the contrast difference between different elements (Z-contrast imaging). As the atomic number difference between $\operatorname{Ag}(47)$ and $\operatorname{Au}(79)$ is rather high, $\mathrm{Z}$ contrast imaging can distinguish the $\mathrm{Au}$ and $\mathrm{Ag}$ within the nanoparticles [23]. Figure 4(a) presents a typical HAADF-STEM image of quasi-spherical core-shell $\mathrm{Au}_{5 \mathrm{~nm}}(\mathrm{PC}) @ \mathrm{Ag} \mathrm{NPs}$ (sample 1 in table 1) with Au core and Ag shell in bright and darker contrast respectively. 
This is further verified by the corresponding EELS maps (figure 4(b)). A silver thickness $e=$ $0.6 \mathrm{~nm}$ is estimated in agreement with the value deduced from TEM images $(e=0.5 \mathrm{~nm}$ see Table 1). However, this latter value is less precise, due to a sampling difference. In fact, a minimum of 500 particles were measured by TEM compared to about ten particles by STEMHAADF. More generally, we observe polycrystalline NPs including multiply-twinned particles (MTP) with tetrahedral sub-units corresponding to an icosahedron (see arrow on figure 4(a)). Furthermore, it is important to note that because of their low size distribution, the $\mathrm{Au}_{5 \mathrm{~nm}}(\mathrm{PC}) @ \mathrm{Ag}$ NPs self-organize into a 2D hexagonal network [39].
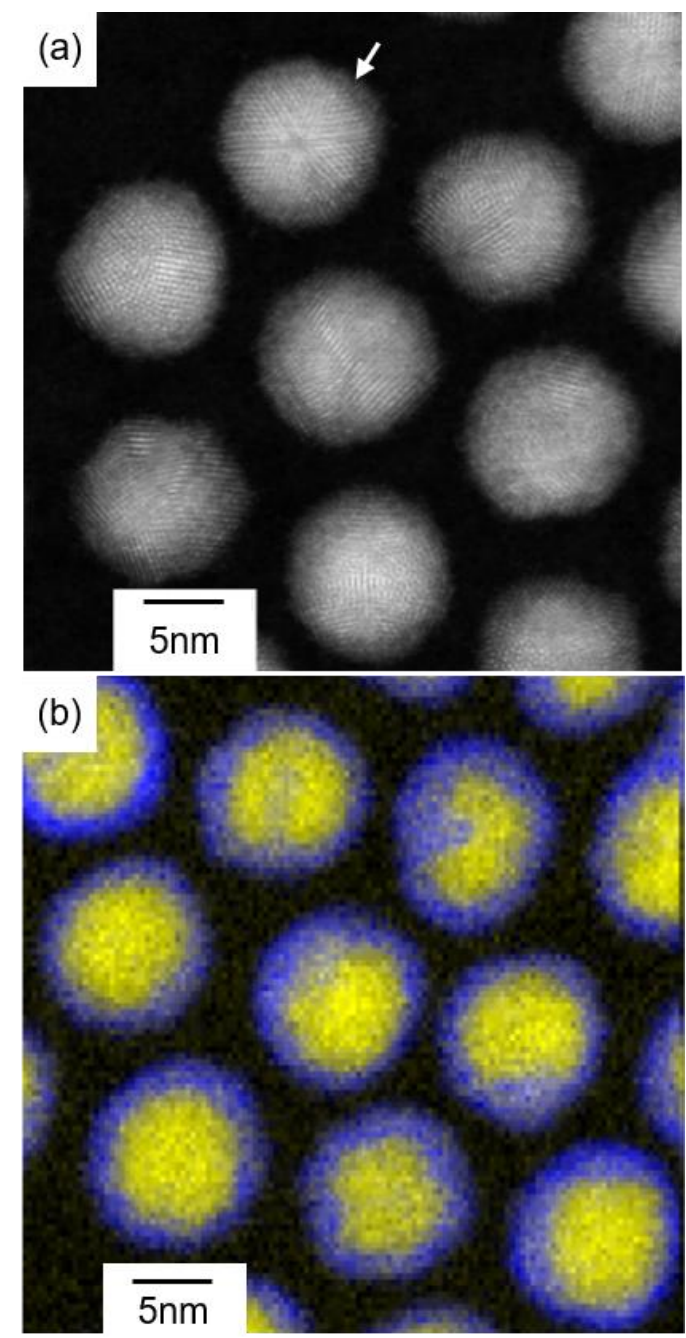

Figure 4. Electron microscopy characterization of Au@Ag core-shell NPs (a) Typical HAADF-STEM dark field image of $\mathrm{Au}_{5 \mathrm{~nm}}(\mathrm{PC}) @ \mathrm{Ag}$ NPs obtained for $\mathrm{C}_{\text {seed }}=1.4 \mu \mathrm{mol} \mathrm{L} \mathrm{L}^{-1}$, the white arrow indicates an icosahedral NP (b) corresponding EELS map showing the Au core (yellow) and the silver shell (blue).

When using $\mathrm{Au}_{10 \mathrm{~nm}}(\mathrm{PC})-\mathrm{C}_{18} \mathrm{NPs}$ as seeds, the silver shell overgrowth takes place during annealing at $90^{\circ} \mathrm{C}$ for only 2 hours. The TEM images confirm the formation of core-shell 
$\mathrm{Au}_{10 \mathrm{~nm}}(\mathrm{PC}) @ \mathrm{Ag} \mathrm{NPs}$ with a total diameter $D_{C S}=12.2 \pm 1.0,14 \pm 1.0$ or $14.8 \pm 1.2 \mathrm{~nm}$ obtained for three seed concentrations $\mathrm{C}_{\text {seed }}, \mathrm{C}_{\text {seed }} / 2$ and $\mathrm{C}_{\text {seed }} / 4$ respectively, with a clear difference of contrast between the core and the shell (figures 5(a)-(c) and insets, Table 2). The corresponding size histograms show narrow size distributions: around 8\% (figures 5(d)-(f)). Furthermore, the silver shell volumes $\left(\mathrm{V}_{\text {shell }}\right)$ directly linked to the overall amount of $\mathrm{Ag}$ deposited in the shell were calculated for $\mathrm{Au}_{10 \mathrm{~nm}} @ \mathrm{Ag}$ and $\mathrm{Au}_{5 \mathrm{~nm}} @ \mathrm{Ag}$ core-shell NPs. These calculations allow us to compare shell growth kinetics on both sizes of seed (Tables 1 and 2). For similar gold seed concentrations and $\mathrm{R}$ values, $\mathrm{V}_{\text {shell }}$ values for $\mathrm{Au}_{10 \mathrm{~nm}}-\mathrm{C}_{18} @ \mathrm{Au}$ NPs are significantly higher than those obtained for $\mathrm{Au}_{5 \mathrm{~nm}}(\mathrm{PC})-\mathrm{C}_{12} @ \mathrm{Ag}$ NPs (see Tables 1 and 2).

Table 2: Experimental conditions used for the preparation of $\mathrm{Au}_{10 \mathrm{~nm}}(\mathrm{PC}) @ \mathrm{Ag} \mathrm{NPs}$, where e is the silver shell thickness, $\mathrm{V}_{\text {shell }}$ is the silver shell volume $\left(\mathrm{V}_{\text {shell }}=\mathrm{V}_{\mathrm{Au} @ \mathrm{Ag}}-\mathrm{V}_{\mathrm{Au} \text { seed }}\right) \mathrm{R}$ is the [Ag precursor] / [Au seed] concentration ratio.

\begin{tabular}{lccccc}
\hline Samples & $\begin{array}{c}{[\mathrm{Au} \text { seed }]} \\
\left.(\mu \mathrm{mol} \mathrm{L})^{-1}\right)\end{array}$ & $\begin{array}{c}{\left[\mathrm{Ag}^{+}\right]} \\
\left(\mathrm{mmol} \mathrm{L}^{-1}\right)\end{array}$ & $\begin{array}{c}e \\
(\mathrm{~nm})\end{array}$ & $\begin{array}{c}\mathrm{V}_{\text {Shell }} \\
\left(\mathrm{nm}^{3}\right)\end{array}$ & $\mathrm{R}$ \\
\hline 6 & 1.4 & 0.825 & 0.8 & 327 & 600 \\
7 & 0.7 & 0.825 & 1.7 & 813 & 1200 \\
8 & 0.35 & 0.825 & 2.1 & 1073 & 2400
\end{tabular}

The silver growth process is thus faster and more efficient on $\mathrm{Au}_{10 \mathrm{~nm}}-\mathrm{C}_{18}$ than on $\mathrm{Au}_{5 \mathrm{~nm}}-\mathrm{C}_{12}$. Larger nanoparticle sizes indeed offer a larger surface area accessible to silver ions, which promotes the growth of the silver layer and gives a greater silver thickness than on smaller nanoparticles. In addition, silver is deposited on the $\mathrm{Au}$ area in the presence of a capping agent. The silver growth process thus requires a desorption of the capping layer, deposition of $\mathrm{Ag}$ on the exposed $\mathrm{Au}$ surface and subsequent re-encapsulation of the Au surface by the capping agents [40]. Oleylamine as a capping agent is more weakly bound to the gold surface than dodecanethiol and is very labile $[41,42]$, thereby promoting the growth of silver on the gold surface.

A typical HRTEM image of $\mathrm{Au}_{10 \mathrm{~nm}}(\mathrm{PC}) @ \mathrm{Ag}$ NPs with overall size $12.2 \pm 1.0 \mathrm{~nm}$ after the silver shell growth is shown in figure 6. The icosahedral particle with rather rounded edges shows a dark central part and a brighter outer part in agreement with a gold core and a silver shell. Moreover, the HRTEM image suggests an epitaxial growth relationship between the 
icosahedral $\mathrm{Au}$ core and $\mathrm{Ag}$ shell as the growth of the shell perfectly follows the morphology of the underlying gold core.
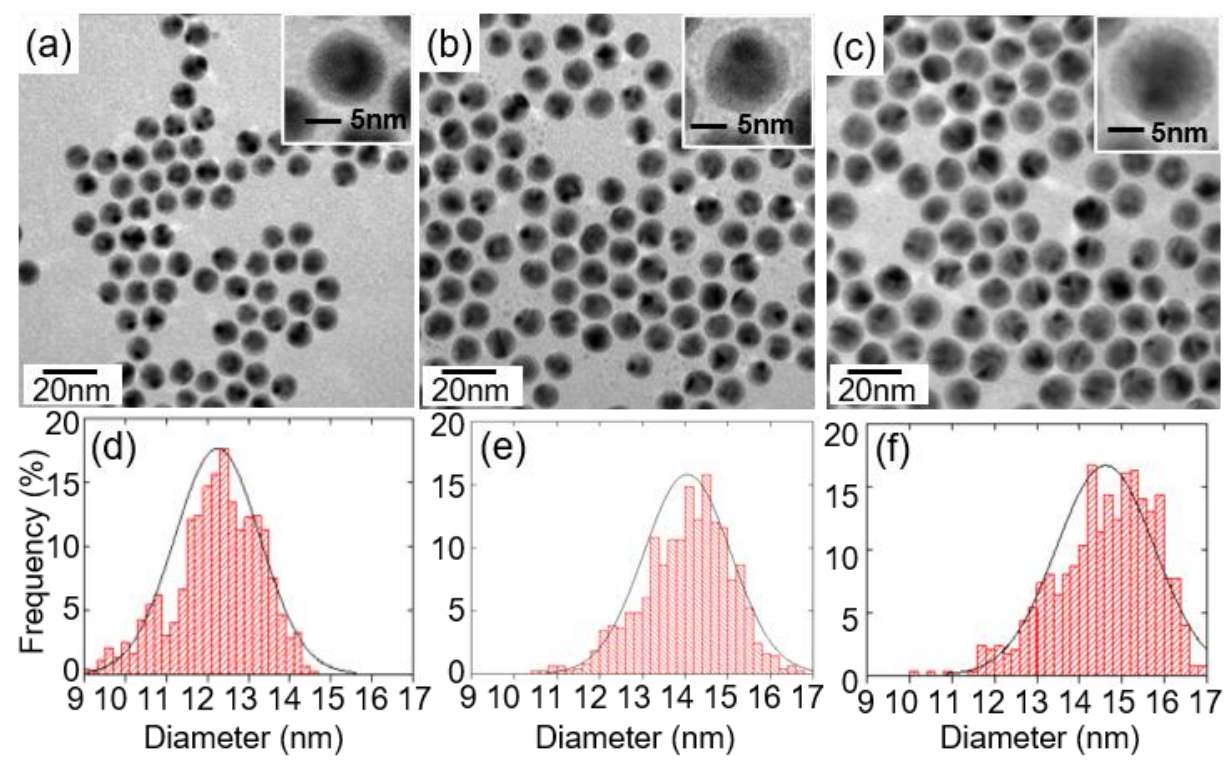

Figure 5. Representative TEM images of $\mathrm{Au}_{10 \mathrm{~nm}}(\mathrm{PC}) @ \mathrm{Ag}$ core-shell NPs from different seed concentrations (a) $\mathrm{C}_{\text {seed }}$, (b) $\mathrm{C}_{\text {seed }} / 2$, (c) $\mathrm{C}_{\text {seed }} / 4$ where $\mathrm{C}=1.4 \mu \mathrm{mol} \mathrm{L} \mathrm{L}^{-1}$ and $(\mathrm{d}, \mathrm{e}, \mathrm{f}$ ) the corresponding size histograms. In inset: representative TEM images at higher magnification

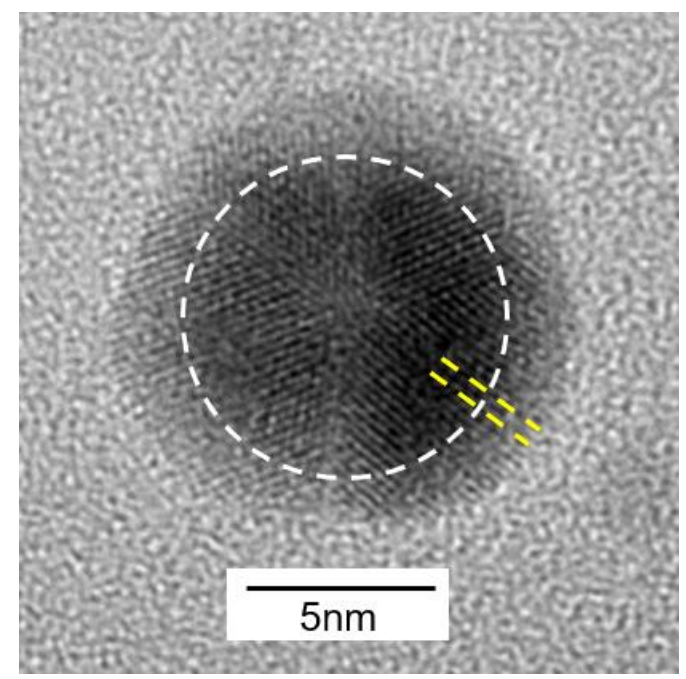

Figure 6. Typical HRTEM image of $\mathrm{Au}_{10 \mathrm{~nm}}(\mathrm{PC}) @ \mathrm{Ag}$ NPs obtained for $\mathrm{C}_{\text {seed }}=1.4 \mu \mathrm{mol} . \mathrm{L}^{-1}$. The white circle delineates the gold core-silver shell interface and the yellow dotted lines illustrate the epitaxial relationship between the core and the shell.

2.2 Synthesis of Au@Ag core-shell nanoparticles from SC Au seeds. 
Figure 7(a) is a typical TEM image of $\mathrm{SC} \mathrm{Au}_{5 \mathrm{~nm}}$ NPs with an average diameter of $5.8 \pm 0.3$ $\mathrm{nm}$ obtained after crystallinity selection (see experimental section). Most of the NPs shown exhibit indeed a homogeneous contrast which clearly indicates their single-crystalline structure. The corresponding high resolution TEM image and Fourier transform of the image (figure 7(b) and inset) show that these NPs are single crystal cuboctahedrons (or truncated octahedrons).
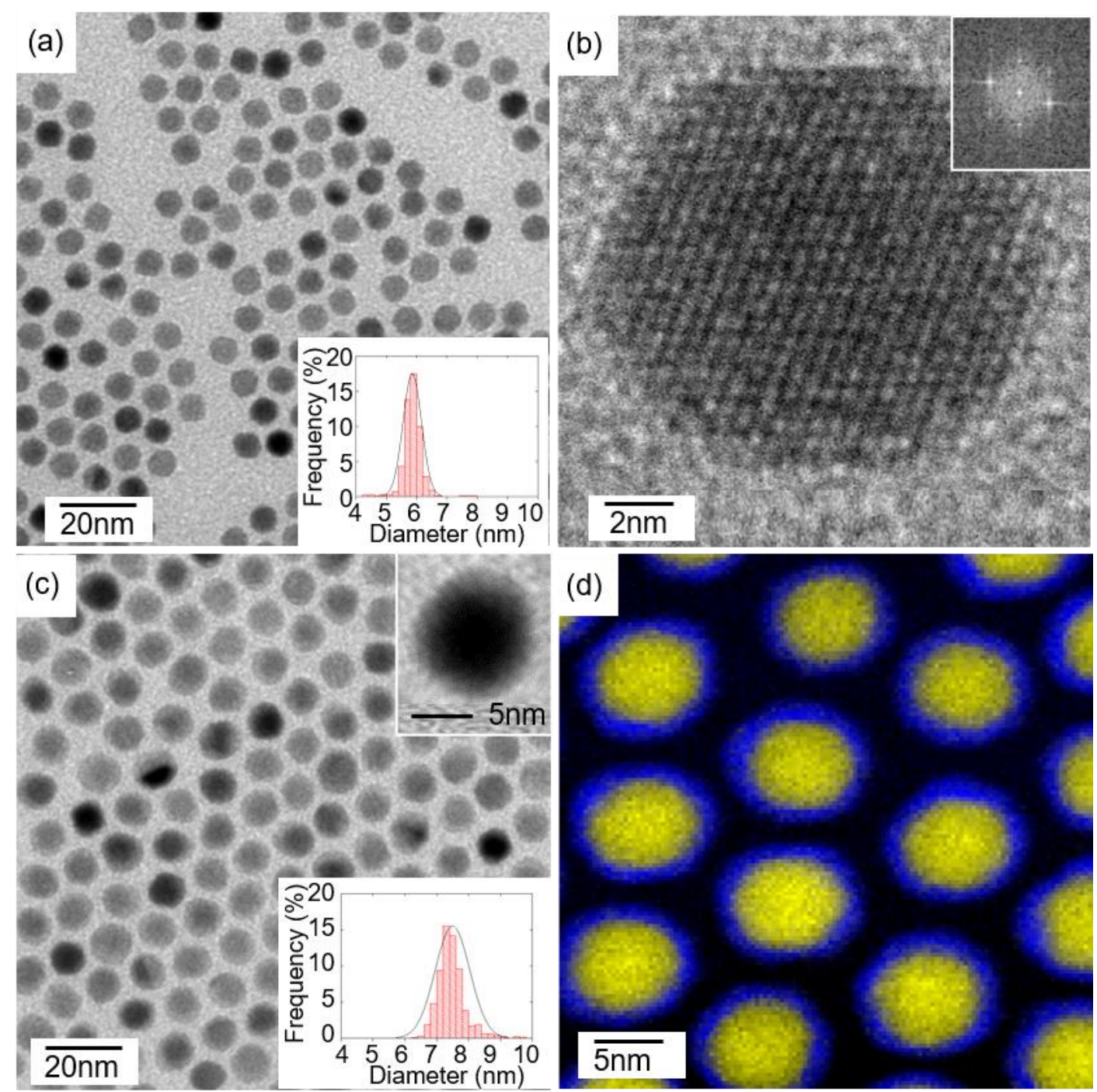

Figure 7. Electron microscopy characterizations: (a) TEM images of $\mathrm{Au}_{5 \mathrm{~nm}}(\mathrm{SC}$ ) seeds, (b) the corresponding HRTEM image and corresponding FFT (c) typical TEM image of $\mathrm{Au}_{5 \mathrm{~nm}}(\mathrm{SC}) @ \mathrm{Ag}$ core-shell NPs with an overall size $=7.5 \pm 0.5 \mathrm{~nm}$ and $(\mathrm{d})$ corresponding EELS map showing the Au core (yellow) and the silver shell (blue).

The silver shell overgrowth was induced as previously in a solution of Ag-oleylamine complex under an annealing temperature of $90^{\circ} \mathrm{C}$ and with concentrations in $\mathrm{Ag}^{+}$ions and 
$\mathrm{Au}_{5 \mathrm{~nm}}(\mathrm{SC})$ seeds of $\mathrm{C}_{\mathrm{Ag}}{ }^{+}=0.825 \mathrm{mmol} \mathrm{L}^{-1}$ and $\mathrm{C}_{\text {seed }}=1.4 \mu \mathrm{mol} \mathrm{L}{ }^{-1}$ respectively and $\mathrm{R}=[\mathrm{Ag}$ precursor $] /[\mathrm{Au}$ seed $]=600$. The size of the NPs is slightly increased and the deduced average Ag thickness of $0.2 \mathrm{~nm}$ is around half that obtained on PC $\mathrm{Au}_{5 \mathrm{~nm}}$ seeds in similar conditions (see figures S2(a) and S2(b) in supporting information). The silver shell appears thus to grow faster on PC Au seeds. This is consistent with the fact that PC NPs present more corners and edges which are sub-coordinated atomic sites of higher energy and hence more active for the heterogeneous nucleation of $\mathrm{Ag}$ at the $\mathrm{Au}$ surface. When the Ag-oleylamine complex concentration is doubled $\left(\mathrm{C}_{\mathrm{Ag}}{ }^{+}=1.65 \mathrm{mmol} \mathrm{L}{ }^{-1}, \mathrm{R}=1200\right)$, the SC nanoparticles flocculate after a reaction time of 1 hour due to a significant increase in their sizes and thus in van der Waals attractions but also due to a tendency to assemble originating from the atomic alignment between their facets [43]. A slight decrease in the heating temperature to $80^{\circ} \mathrm{C}$ (keeping $\mathrm{C}_{\mathrm{Ag}}{ }^{+}=1.65 \mathrm{mmol} \mathrm{L}^{-1}, \mathrm{R}=1200$ ) was observed to slow down the growth of silver on the gold surface, leading to an average silver thickness around 4 times greater than previously $(e=0.85$ $\mathrm{nm}$ ) (figure 7(c)). Furthermore, the TEM image in inset figure 7(c) confirms the formation of core-shell Au@Ag NPs via the difference of contrast between the core and the shell. The core-shell structure is further verified by the EELS map (figure 7(d)). An average silver thickness $e$ around $1 \mathrm{~nm}$ is estimated and is close to the value deduced from TEM images.

\subsection{Dorganization of Au@Ag core-shell.}

After deposition of colloidal solution drops on a silicon substrate and solvent evaporation (toluene in this case) the Au NPs, irrespective of their size $(\sim 5$ or $\sim 10 \mathrm{~nm})$, coating agent (dodecanethiol or oleylamine) or crystallinity (SC or PC), self-organize to form well facetted 3D superlattices (SLs) as is shown in the SEM images (see figures S3 (a), S3(d) and S3(g) in supporting information). Similar SL sizes are obtained whatever the NP size, capping agent and crystallinity. Nevertheless, the SLs shapes are better defined, with the appearance of triangular shaped SLs, for higher NP sizes and for SC NPs. These well-defined shapes are characteristic of homogeneous growth in solution that could be favored by an increase in NPNP interactions between larger NPs due to larger van der Waals interactions or between SC NPs due to the presence of larger facets $[44,45]$. Furthermore, previous results showed that the nature of the interactions between NPs (attractive or repulsive) depend both on the nature of the capping agent and the van der Waals attractions between the cores for a given solvent $[44,45]$. Although the interdigitation is partial for oleylamine molecules (unlike dodecanethiols) due to the $\mathrm{C}=\mathrm{C}$ double bond [46], a larger metal core size can still induce 3D organization into colloidal crystals. Ordered assemblies of gold NPs 16 to $21 \mathrm{~nm}$ in diameter 
coated with oleylamine have indeed been reported in the literature [41] as well as $11 \mathrm{~nm}$ diameter $\mathrm{Fe}_{\mathrm{X}} \mathrm{O} / \mathrm{CoFe}_{2} \mathrm{O}_{4}$ NPs coated with oleic acids of molecular structure comparable to oleylamine [47].

After silver layer overgrowth, Au@Ag NPs form 3D SLs with similar sizes and shapes to those obtained from the Au seeds, whatever their overall size (see figure S3 in supporting information). This is consistent with a uniform Ag overgrowth, maintaining a low size and shape distribution of the core-shell NPs.

A HRSEM image and corresponding Fourier transform of a typical 3D superlattice made of $\mathrm{Au}_{10 \mathrm{~nm}}(\mathrm{PC}) @ \mathrm{Ag}$ core-shell NPs with average overall size of $14 \mathrm{~nm}$ demonstrates that the nanoparticles are well ordered in a compact surface plane corresponding to the [111] fcc orientation (figure 8(a) and inset). At higher magnification, the HRSEM image (figure 8(b)) shows clearly the stacking of NP monolayers organized in a hexagonal network.

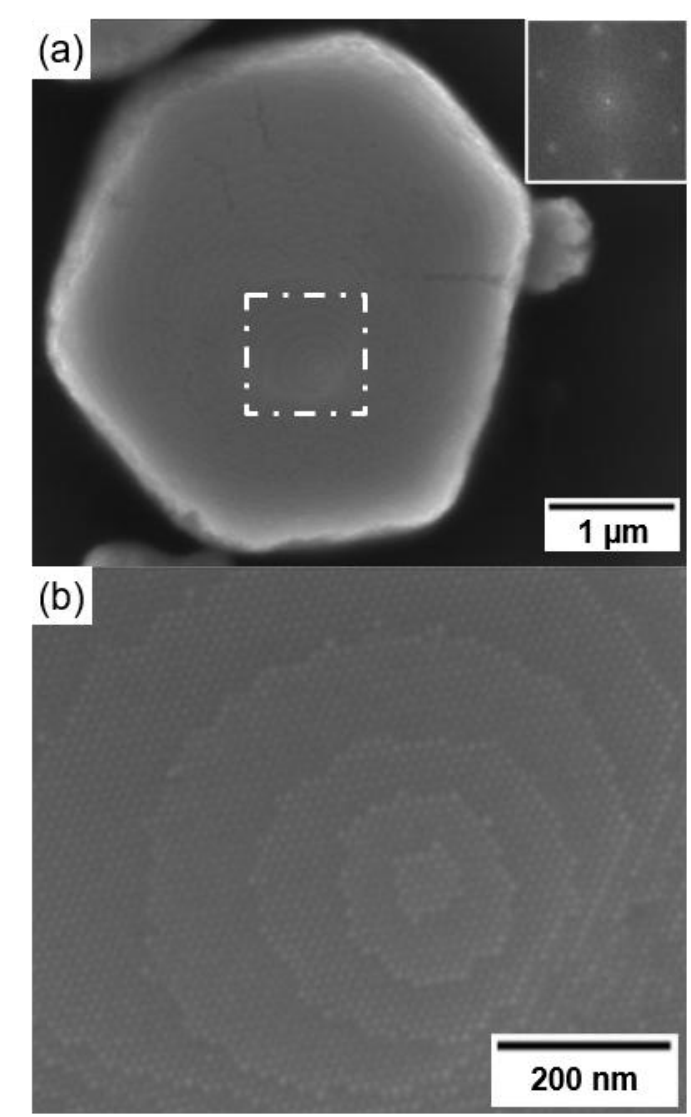

Figure 8. HR-SEM image (a) of colloidal crystal made of core-shell $\mathrm{Au}_{10 \mathrm{~nm}}(\mathrm{PC}) @ \mathrm{Ag} \mathrm{NPs}$ with overall size of $14 \mathrm{~nm}$ after the shell growth. In inset the corresponding Fourier transform. (b) Magnified HR-SEM image of the area delimited by white rectangle in a.

All these samples were also analyzed by EDS in the SEM to determine the NP composition. When the measured variation? does not exceed one percent, we consider such NPs to be 
homogeneous in composition. EDS measurements confirm the homogeneous composition of the bimetallic nanoparticles everywhere on the substrate and agree with the atomic compositions calculated from the core-shell structures deduced from TEM images (see Table $\mathrm{S} 1$ in supporting information).

\subsection{Optical properties of $A u(P C) @ A g N P s$}

We studied the optical properties of $\sim 5 \mathrm{~nm}$ and $\sim 10 \mathrm{~nm} \mathrm{Au} @ \mathrm{Ag}$ NPs formed only from polycrystalline gold cores, through UV-visible absorption measurements (figure 9). The spectra were recorded from colloidal solutions at room temperature with a fixed concentration of $0.14 \mu \mathrm{mol} \mathrm{L}-1$.

(a) $\mathrm{Au}_{5 \mathrm{~nm}}(\mathrm{PC}) @ \mathrm{Ag}$ NPs

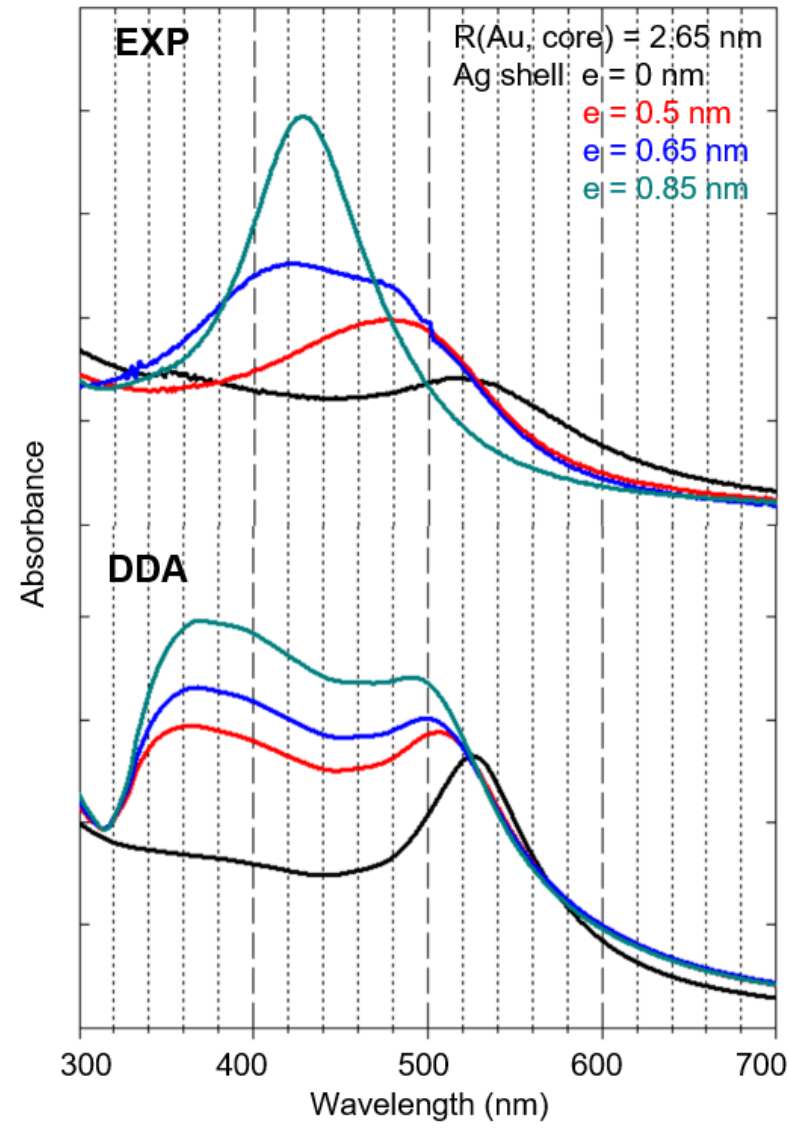

(b) $\mathrm{Au}_{10 \mathrm{~nm}}(\mathrm{PC}) @ \mathrm{Ag} \mathrm{NPs}$

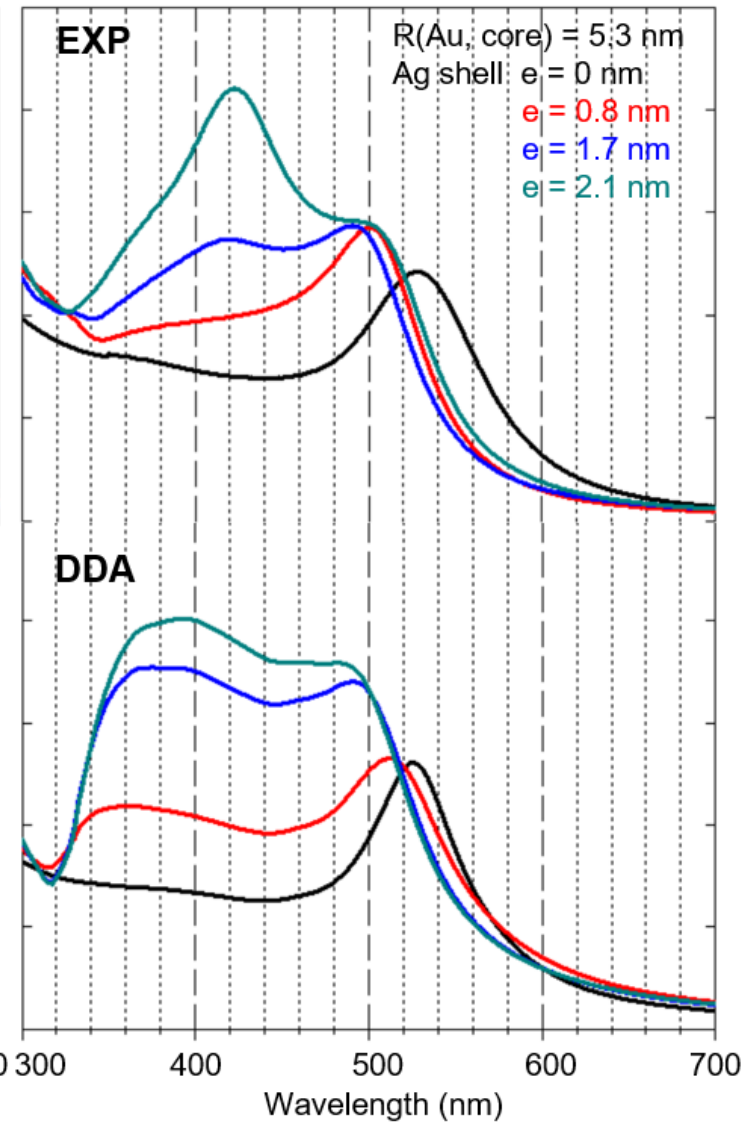

Figure 9. Experimental and DDA calculated absorption spectra of core-shell (a) $\mathrm{Au}_{5 \mathrm{~nm}}(\mathrm{PC}) @ \mathrm{Ag} \mathrm{NPs}$ and (b) $\mathrm{Au}_{10 \mathrm{~nm}}(\mathrm{PC}) @ \mathrm{Ag}$ NPs with various shell thicknesses as indicated in both panels 
Significant changes are observed in the UV-visible spectra depending on the core size and composition of the $\mathrm{Au}(\mathrm{PC}) @ \mathrm{Ag}$ NPs (figures 9(a) and 9(b)). In figure 9(a), $\mathrm{Au}_{5 \mathrm{~nm}}(\mathrm{PC})$ seeds exhibit an absorbance band at $520 \mathrm{~nm}$ corresponding to the surface plasmon resonance (SPR) of the nanoparticles. For core-shell $\mathrm{Au}_{5 \mathrm{~nm}}$ (PC)@Ag NPs, a blue shift (30 nm) and an increase in the SPR band intensity are observed when the Ag shell grows to $e=0.5 \mathrm{~nm}$ thickness $(\sim 1$ atomic layer). When the thickness of the silver layer reaches $0.65 \mathrm{~nm}(\sim 2$ atomic layers), the SPR band appears to be structured, with two components centered at $410 \mathrm{~nm}$ and $490 \mathrm{~nm}$. The higher-wavelength SPR component is attributed to the $\mathrm{Au}$ core while the other one corresponds to the silver shell $[9,10,12]$. Finally, the absorption spectrum of $\mathrm{Au}_{5 \mathrm{~nm}}(\mathrm{PC}) @ \mathrm{Ag}$ NPs with around $3 \mathrm{Ag}$ atomic layers $(e=0.85 \mathrm{~nm}$ ) only exhibits the low-wavelength SPR component whose profile and wavelength correspond to the SPR of silver NPs of similar size. This experiment was reproduced several times. It seems that the absorption of the silver shell is dominant in spite of its thinness. In the case of $\mathrm{Au}_{10 \mathrm{~nm}}(\mathrm{PC})$ seeds, a sharp and narrow SPR band centered at $530 \mathrm{~nm}$ is observed (figure 9(a) below). After the growth of a silver shell of thickness $0.8 \mathrm{~nm}(\sim 3$ atomic layers $)$ the SPR band becomes more intense and shifts to the blue at $510 \mathrm{~nm}$ while a shoulder starts to grow on the low-wavelength side of the SPR. When the silver thickness is further increased to reach $e=1.7 \mathrm{~nm}$ ( $\sim 5$ atomic layers), two SPR components are observed at 505 and $405 \mathrm{~nm}$. As previously, the splitting into two components arises from the respective contributions of the gold core and the silver shell to the absorption. Finally, for a silver thickness of $2.1 \mathrm{~nm}$ ( $\sim 6$ atomic layers) the lower-wavelength SPR component attributed to the Ag shell becomes dominant.

We thus experimentally observe that SPR features of Au@Ag NPs are significantly modulated by the layer thickness and core size in agreement with the literature $[18,48]$.

To gain deeper insights into the relationship between the SPR bands and the core size and shell thickness of the Au@Ag NPs, DDA calculations were carried out to simulate the absorption spectra of $\mathrm{Au}_{5 \mathrm{~nm}}(\mathrm{PC}) @ \mathrm{Ag}$ and $\mathrm{Au}_{10 \mathrm{~nm}}(\mathrm{PC}) @ \mathrm{Ag}$ core-shell NPs [9]. In these calculations, the refractive index of the surrounding medium is set to 1.5 to simulate the toluene used as the solvent [49]. The size-corrected complex dielectric functions for Ag shells and $\mathrm{Au}$ cores were calculated according to the procedure described in the supporting information. The calculated spectra obtained for different Au core sizes and silver shell thicknesses are plotted in figure 9(b) and are consistent with the general trend observed in the experimental spectra. Nevertheless, for the $\mathrm{Au}_{10 \mathrm{~nm}}(\mathrm{PC}) @ \mathrm{Ag}$ NPs spectra, the contribution from the silver component increases with the shell thickness but remains slightly smaller than 
in the experiment. For $\mathrm{Au}_{5 \mathrm{~nm}}(\mathrm{PC}) @ \mathrm{Ag} \mathrm{NPs}$, in each calculated spectrum, the contribution of the gold core remains more pronounced whatever the silver shell thickness, although it decreases with the thickness of silver layer as experimentally observed. The disagreement is greatest when the number of silver layers reaches 3 . The discrepancies between the experimental and calculated spectra may arise from the slight deviation from the ideal concentric spherical shape, as revealed in figure 4(b) by the EELS mapping of the core-shell NPs and also from a more or less uniform shell thickness especially as it increases (see the HRTEM image of $\mathrm{Au}_{10 \mathrm{~nm}} @ \mathrm{Ag}$ NPs in figure 6). The presence of pure Ag NPs in coexistence with core-shell Au@Ag NPs, which could explain the more pronounced contribution of the silver component in the experimental spectra must be excluded according to the EDS results (see table S1 in supporting information) and LFRS spectra performed on these samples (figure 10). Finally, we can note that the peak corresponding to the contribution of silver to the plasmon resonance appears at shorter wavelengths in all simulated spectra than in experimental ones. We cannot exclude an $\mathrm{Au}-\mathrm{Ag}$ alloy layer at the interface according to EELS profiles (see figure S4 in supporting information). The interface width in the $\mathrm{Au}(\mathrm{SC}) @ \mathrm{Ag}$ NPs (figure 7) is no more than $1 \mathrm{~nm}$, with a likely value of half of this or less, corresponding to about 1 unit cell. The $\mathrm{Au}(\mathrm{PC}) @ \mathrm{Ag}$ nanoparticles are more difficult to analyze in this way, with some localized regions in which the silver layer penetrates further into the gold (figure 4). Nevertheless, there is no particular reason to believe the interface width here would be significantly different. This alloy layer could disturb the optical spectra and be at the origin of the disagreement with the DDA calculations.

\subsection{Effect of Ag shell growth on acoustic vibrations of Au@Ag NPs}

Acoustic vibrations of $\mathrm{Au}_{5 \mathrm{~nm}}(\mathrm{PC}) @ \mathrm{Ag}, \mathrm{Au}_{5 \mathrm{~nm}}(\mathrm{SC}) @ \mathrm{Ag}$ and $\mathrm{Au}_{10 \mathrm{~nm}}(\mathrm{PC}) @ \mathrm{Ag}$ core-shell NPs with different silver shell thicknesses were investigated by LFRS to confirm the crystallinity of the Au core and to study the strength of the core-shell bond. The corresponding Stokes and anti-Stokes LFRS spectra are presented in figure 10. Each spectrum obtained from $\mathrm{Au}_{5 \mathrm{~nm}}(\mathrm{PC}) @ \mathrm{Ag}$ and $\mathrm{Au}_{10 \mathrm{~nm}}(\mathrm{PC}) @ \mathrm{Ag}$ core-shell NPs (figures 10(a) and 10(b)) exhibits an intense band ascribed to the Raman scattering by the quadrupolar vibrational mode of the NPs. Whatever the $D_{C O R E}$ value, this band shifts towards lower frequencies when the shell thickness is increased. Such a behavior qualitatively agrees with the usual dependence of the vibrational frequencies on the inverse of the NP diameter [50]. The measured frequencies at the maximum of the quadrupolar band are listed in Table 3 and compared to those calculated 
using a model based on Lamb's theory [51] and Eringen and Suhubi's equations [52]. The same approach was already described in a previous work [53] to numerically determine the frequencies of the free vibrational modes of core-shell and onion-like systems.
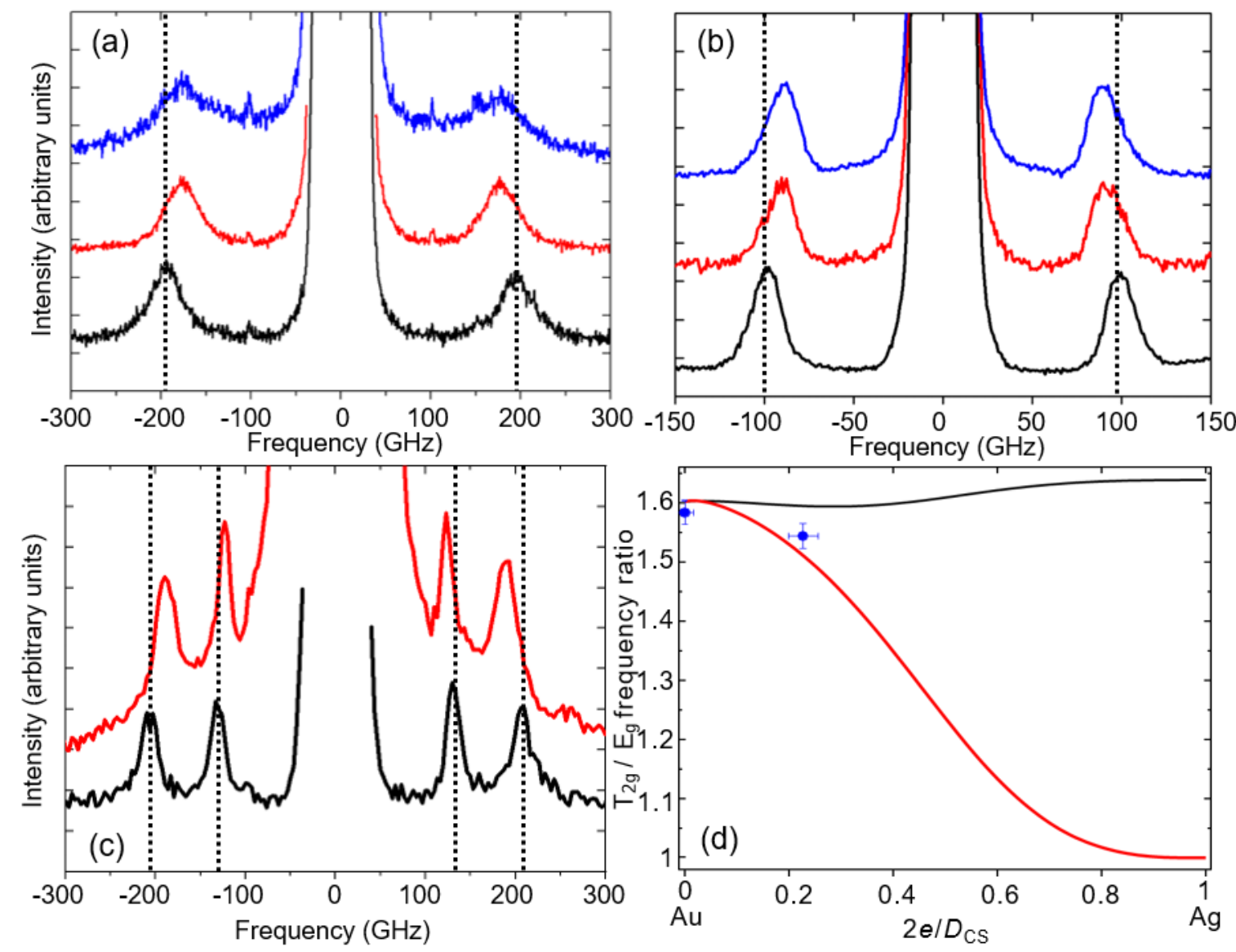

Figure 10. Stokes / anti-Stokes Raman scattering spectra of Au@Ag core-shell NPs with different silver thicknesses $e$ and core crystallinities (PC or SC). (a) Comparison of the spectrum of $\mathrm{Au}_{5 \mathrm{~nm}}(\mathrm{PC}) \mathrm{NPs}$ (black curve) with those of $\mathrm{Au}_{5 \mathrm{~nm}}(\mathrm{PC}) @ \mathrm{Ag}$ with $e=0.5 \mathrm{~nm}$ (red curve) or $0.65 \mathrm{~nm}$ (blue curve). (b) Comparison of the spectrum of $\mathrm{Au}_{10 \mathrm{~nm}}(\mathrm{PC}) \mathrm{NPs}$ (black curve) with those of $\mathrm{Au}_{10 \mathrm{~nm}}(\mathrm{PC}) @ \mathrm{Ag}$ NPs with $e=0.8 \mathrm{~nm}$ (red curve) or $1.7 \mathrm{~nm}$ (blue curve). (c) Comparison of the spectrum of $\mathrm{Au}_{5 \mathrm{~nm}}(\mathrm{SC}) \mathrm{NPs}$ (black curve) with those of $\mathrm{Au}_{5 \mathrm{~nm}}(\mathrm{SC}) @ \mathrm{Ag} \mathrm{NPs}$ with $e=0.85 \mathrm{~nm}$ (red curve). All the spectra are normalized and vertically shifted for clarity. (d) Calculated and measured (blue points) $T_{2 g} / E_{g}$ frequency ratio of $\mathrm{Au}_{5 \mathrm{~nm}}(\mathrm{SC}) @ \mathrm{Ag}$ NPs as a function of the relative shell thickness variation defined by $2 e / D_{C S}$ for epitaxial (black curve) and isotropic silver shell (red curve). 
Table 3 Measured quadrupolar vibrational mode frequencies of $\left.\mathrm{Au}_{5 \mathrm{~nm}}(\mathrm{PC})\right) @ \mathrm{Ag}$ and $\left.\mathrm{Au}_{10 \mathrm{~nm}}(\mathrm{PC})\right) @ \mathrm{Ag}$ core-shell NPs compared to those calculated for a free elastic isotropic nanosphere with a gold core - silver shell structure. The thickness $e$ is equal to $\left(D_{C O R E}-\right.$ $\left.D_{C S}\right) / 2$.

\begin{tabular}{ccccc}
\hline$D_{\text {CORE }}(\mathrm{nm})$ & $D_{C S}(\mathrm{~nm})$ & $e(\mathrm{~nm})$ & $\begin{array}{c}\text { Measured } \\
\text { frequency } \\
(\mathrm{GHz})\end{array}$ & $\begin{array}{c}\text { Calculated } \\
\text { frequency } \\
(\mathrm{GHz})\end{array}$ \\
\hline 5.3 & - & - & 199 & 200 \\
5.3 & 6.3 & 0.50 & 177 & 185 \\
5.3 & 6.6 & 0.65 & 171 & 181 \\
10.6 & - & - & 100 & 100 \\
10.6 & 12.2 & 0.80 & 91 & 92 \\
10.6 & 14.0 & 1.70 & 88 & 88
\end{tabular}

For the Au(PC)@Ag NPs the calculated vibrational frequencies reported in Table 3 are in good agreement with the measured ones, especially for the largest values of $D_{\text {CORE. Although }}$ the NPs self-assemble to form 3D superlattices (see figure S3 in supporting information), in which they are in contact with neighboring NPs via the capping agents, their acoustic vibrations are successfully estimated in the frame of a free elastic sphere model. The calculated frequencies are determined by modeling the core-shell NPs as free elastic spheres made of a gold core and a silver shell. Both materials are assumed to have isotropic elasticity. The transverse and longitudinal sound velocities used for gold and silver are respectively $\mathrm{v}_{\mathrm{t}}[\mathrm{Au}]=1250 \mathrm{~m} \mathrm{~s}^{-1}, \mathrm{v}_{\mathrm{t}}[\mathrm{Ag}]=1740 \mathrm{~m} \mathrm{~s}^{-1}, \mathrm{v}_{\mathrm{l}}[\mathrm{Au}]=3330 \mathrm{~m} \mathrm{~s}^{-1}$ and $\mathrm{v}_{\mathrm{l}}[\mathrm{Ag}]=3747 \mathrm{~m} \mathrm{~s}^{-1}$. In addition, to mimic a perfect contact between the core and shell materials, it is assumed that there is continuity of both the vibrational displacement and the force at the Au/Ag interface. The agreement between the measured and calculated vibrational frequencies supports the core-shell structure of the NPs, i.e. the separation of the two metals. Moreover, it makes sense from this comparison to infer a perfect contact between the gold core and the silver shell. For the $\mathrm{Au}_{5 \mathrm{~nm}}(\mathrm{SC})$ seeds and the corresponding $\mathrm{Au}_{5 \mathrm{~nm}}(\mathrm{SC}) @ \mathrm{Ag}$ NPs with a total diameter $D_{C S}$ of $7.5 \mathrm{~nm}$, two bands are observed and correspond to a splitting of the quadrupolar vibration into two components (figure 10(c)) which was shown in previous papers as being an effect of crystallinity $[43,54,55]$. This quadrupolar mode splitting into $E_{\mathrm{g}}$ and $T_{2 \mathrm{~g}}$ modes is related to the variation of the transverse sound speeds with the propagation direction of 
phonons in the cubic lattice. The ratio of the calculated frequencies of the $T_{2 g}$ and $E_{g}$ peaks is about 1.6 for gold, which makes it a powerful indicator of the crystallinity of the NPs. Calculations for core-shell NPs were performed for an $\mathrm{Au}(\mathrm{SC})$ core surrounded by a shell made of either epitaxial or multiply-twinned silver (modeled as isotropic silver) with varying thicknesses, using the elastic constants for bulk materials [56] and the sound speeds given above for the isotropic approximation of silver (see table S2 in supporting information). We focus on the $T_{2 \mathrm{~g}} / E_{\mathrm{g}}$ frequency ratio in the following to monitor the elastic anisotropy of the core-shell NPs. The results are presented in figure 10(d). The shell thickness variation is represented by $2 e / D_{C S}$. On the left side of the graph $(e=0)$ the NPs are $\mathrm{Au}(\mathrm{SC})$. On the right side $\left(e>D_{\text {CORE }}\right.$ ), the core can be neglected and the NPs are $\mathrm{Ag}$ (SC or PC) depending on the model. For an epitaxial silver shell, the $T_{2 g} / E_{g}$ frequency ratio hardly changes with $e$ while in the case of a multiply twinned silver shell the splitting vanishes as e increases. The experimental ratios are also plotted in this graph with error bars indicating the experimental precision. As already reported in previous works, calculations overestimate the experimental splitting for the Au (SC) NPs [55]. As we expect the same to be true for the $\mathrm{Au}(\mathrm{SC}) @ \mathrm{Ag}$ core-shell NPs, we should compare the variations of the $T_{2 g} / E_{g}$ frequency ratio as the shell thickness increases. For the epitaxial silver shell, the variation of the calculated $T_{2 \mathrm{~g}} / E_{\mathrm{g}}$ frequencies ratio between the Au NP and the Ag@ Au NP is small ( 0.008). For the isotropic silver shell, it is about ten times more ( 0.09). The experimental variation falls in between those two values ( 0.04) but with non-negligible error bars. This intermediate value probably indicates that the actual structure of the core-shell $\mathrm{Au}_{5 \mathrm{~nm}}(\mathrm{SC}) @ \mathrm{Ag}$ NPs is more complex than previously thought. We assumed in these calculations an abrupt interface between the core and a shell of a constant thickness. These may be good first-order approximations only. As already discussed before, we cannot rule out the presence of interdiffusion between gold and silver. The presence of such an intermediate layer would modify the frequencies. Also, a thinner shell on the (110) facets of the $\mathrm{Au}(\mathrm{SC}) @ \mathrm{Ag}$ core-shell NPs would increase the calculated $T_{2 g}$ frequencies and improve the agreement between the experimental data and the epitaxial model.

\section{Conclusion}

$\mathrm{Au} @ \mathrm{Ag}$ core-shell NPs were successfully obtained by a versatile and robust synthesis process. Cores of varying sizes and crystallinities were produced that can be coated by 
different types of capping agents. The thickness of the silver shell is shown to be finely controllable via several parameters such as the Au seed and silver ion concentrations, the reaction temperature and annealing time. These conditions are adapted according to the nature of the capping agent, the size of the seeds and their crystallinity. The growth rate of silver is faster when the size of the gold seed increases (from $5 \mathrm{~nm}$ to $10 \mathrm{~nm}$ ) but also when the ligands are more easily desorbed (oleylamine is more weakly bonded to gold surfaces than dodecanethiol) allowing the silver ions to be deposited on the free surface of gold. The growth rate of silver is also faster on $\mathrm{Au}_{5 \mathrm{~nm}}(\mathrm{PC})$ compared to $\mathrm{Au}_{5 \mathrm{~nm}}(\mathrm{SC})$ and this is consistent with the fact that $\mathrm{Au}(\mathrm{PC}) \mathrm{NPs}$ present more active sites (corners and edges) for the heterogeneous nucleation of $\mathrm{Ag}$ at the $\mathrm{Au}$ surface. It is possible to solve this problem by adjusting the silver ion concentration and the reaction temperature. Comparable silver layer thicknesses were obtained on both types of seeds.

By combining UV visible spectrophotometry measurements and DDA calculations, we showed significant changes in the plasmonic response depending on the core size and silver thickness. Finally, the vibrational spectroscopy demonstrated a good control of the core-shell structure of the bimetallic nanoparticles synthesized in this work. The control of the crystallinity of the $\mathrm{Au}$ core for $\mathrm{Au}_{5 \mathrm{~nm}} @ \mathrm{Ag} \mathrm{NPs}$ is also confirmed from PC to SC for $\mathrm{Au}_{5 \mathrm{~nm}} @ \mathrm{Ag}$ NPs by LFRS. Furthermore, micrometer-scale well-faceted 3D superlattices of ordered Au@Ag NPs were obtained and imaged by HR-SEM. The high quality of the NPs, whether in size control, chemical composition or crystallinity makes it possible to envisage these 3D superlattices as new SERS platforms with tunable optical properties $[32,57,58]$. The modulations in size and crystallinity of the core-shell Au@Ag NPs will promote their application in catalysis, where these parameters are known to play a fundamental role $[13,30,31]$. In addition, recent preliminary results have shown that the versatility of this synthesis process allows one to replace both the gold core (with other plasmonic materials such as silver or copper) and the Ag shell (with catalytic materials such as Pt or Pd) all with a fine control of the composition and overall size.

\section{Experimental methods}

All chemicals were used without further purification. 1-dodecanethiol $(\geq 98 \%)$, hexane $(\geq$ 99\%) and ethanol absolute $(\geq 99 \%)$ were purchased from Sigma-Aldrich. Tert-butylamine borane complex $(\geq 97 \%)$ is from STREM Chemicals. Toluene $(\geq 99 \%)$ and oleylamine $(80$ 90\%) were bought from ACROS Organics. Gold(I) chloride triphenylphosphine $\left(\mathrm{ClAu}\left(\mathrm{PPh}_{3}\right)\right)$ 
was purchased from STREM, gold(I) chloride trihydrate $\left(\mathrm{HAuCl}_{4}\right)$ and silver nitrate $\left(\mathrm{AgNO}_{3}\right)$ from Aldrich.

\subsection{Synthesis of the gold nanoparticles}

\subsection{1 synthesis of $5 \mathrm{~nm}$ dodecanethiol-functionalized Au NPs}

$5 \mathrm{~nm} \mathrm{Au} \mathrm{NPs} \mathrm{were} \mathrm{synthesized} \mathrm{through} \mathrm{a} \mathrm{revisited} \mathrm{method} \mathrm{from} \mathrm{the} \mathrm{Stucky} \mathrm{group} \mathrm{[59,60].}$ Briefly, $0.25 \mathrm{mmol}$ of gold(I) chlorotriphenylphosphine $\left(\mathrm{AuClPPh}_{3}\right)$ complex was dissolved in $25 \mathrm{~mL}$ of toluene with $500 \mu \mathrm{L}$ of 1-dodecanethiol. The gold precursor was reduced by adding a solution of tert-butylamine borane (TBAB) complex $(2.5 \mathrm{mmol}$ dissolved in $5 \mathrm{~mL}$ of toluene). The reaction took place at $100^{\circ} \mathrm{C}$ under vigorous stirring for $5 \mathrm{~min}$. The formation of $\mathrm{Au}$ NPs was evidenced by the color change of the solution from colorless to dark red. After the reaction, a washing step was necessary to remove all by-products. First, all the solvent was evaporated and the same amount of ethanol was added, then the solution was centrifuged at $5000 \mathrm{rpm}$ for $5 \mathrm{~min}$. The precipitate was then dispersed in toluene or hexane. These NPs were a mixture of polycrystals (PC) (decahedra and icosahedra) and single crystals (SC) [61] and were characterized by a narrow size distribution around 8\% (see figure S5 in supporting information). They were then used for the selection in crystallinity and the obtaining of polycrystal (PC) or single crystal (SC) Au seeds of similar diameters around 5nm.

\subsubsection{Synthesis of $10 \mathrm{~nm}$ oleylamine-functionalized Au NPs}

$10 \mathrm{~nm} \mathrm{Au(PC)} \mathrm{NPs} \mathrm{were} \mathrm{synthesized} \mathrm{using} \mathrm{only} \mathrm{two} \mathrm{reagents:} \mathrm{oleylamine} \mathrm{and} \mathrm{gold(III)}$ chloride trihydrate. The ability of oleylamine to act as surfactant, solvent and reducing agent is well known $[62,63]$. The reduction process was carried out via the amine which can undergo induced oxidation by the metal ions to nitrile [41,64]. For the synthesis of $10 \mathrm{~nm}$ spherical Au NPs, a solution of Au-oleylamine complex was produced by dissolving $25 \mathrm{mmol}$ of gold(III) chloride trihydrate in $5 \mathrm{~mL}$ oleylamine at $30^{\circ} \mathrm{C}$ under magnetic stirring for 30 min. The complex formation was evidenced by IR spectroscopy (see figures S6(a) and S6(b) in supporting information), which showed that $\mathrm{Au}$ ions were bonded through $\mathrm{N}-\mathrm{H}$ functional groups to oleylamine. Subsequently, the temperature was increased to $110^{\circ} \mathrm{C}\left(4^{\circ} \mathrm{C} \mathrm{min}^{-1}\right)$ and maintained there for $30 \mathrm{~min}$. The solution was cooled to room temperature and the nanoparticles were precipitated by adding an excess of ethanol and centrifuging at $5000 \mathrm{rpm}$ for $5 \mathrm{~min}$ to remove all the by-products. The supernatant was discarded and the precipitate was dispersed in toluene. 


\subsection{Nanocrystallinity selection of $5 \mathrm{~nm}$ dodecanethiols-functionalized Au NPs}

The crystallinity selection of $5 \mathrm{~nm}$ Au NPs was carried out through a process based on the preferential self-assembly of gold single crystals. This process has been the subject of several articles $[43,61,65]$. Briefly, the washed Au NPs were dispersed in toluene and placed in a closed vessel to avoid solvent evaporation. After 8 days, a black precipitate corresponding to the single crystal (SC) NP superlattices was recovered after centrifugation at $5000 \mathrm{rpm}$ for 10 min and dispersed in isooctane. This solution was then used as $\mathrm{Au}(\mathrm{SC})$ seeds. The supernatant contains the PC Au NPs that were also used as seeds.

\subsection{Synthesis of core-shell Au@Ag NPs with different seed sizes and crystallinity}

Whatever their size or crystallinity (PC or SC), the Au NP seeds have to be washed before the silver growth in order to remove the excess of ligands (oleylamine or dodecanethiols). After adding ethanol, the solution was centrifuged at $2000 \mathrm{rpm}$ for $4 \mathrm{~min}$ and the resulting precipitates were dispersed in $2 \mathrm{~mL}$ of toluene or isooctane for $\mathrm{Au}(\mathrm{PC})$ or $\mathrm{Au}(\mathrm{SC})$ seeds respectively. Isooctane replaced toluene for $\mathrm{Au}(\mathrm{SC}) \mathrm{NPs}$ to avoid their self-assembly into superlattices and thus their precipitation $[43,44,66]$. This step was repeated one more time. The growth of the silver shell was then induced in a solution of Ag-oleylamine complex. This solution is produced by a method adapted from Shen et al [63]. $0.055 \mathrm{mmol}$ of $\mathrm{AgNO}_{3}$ were dissolved in $5 \mathrm{~mL}$ pure oleylamine at $30^{\circ} \mathrm{C}$ and stirred during $30 \mathrm{~min}$. After dissolution, the solution was used immediately. As in the case of Au-oleylamine, the complex formation was evidenced by IR spectroscopy (see figures S6(a) and S6(b) in supporting information), which showed that $\mathrm{Ag}$ ions, like $\mathrm{Au}$ ions, in a gold oleylamine complex are bonded through an N-H functional group to oleylamine. Then $100 \mu \mathrm{L}$ of $\mathrm{Au}$ seed suspension was mixed with $150 \mu \mathrm{L}$ Ag-oleylamine complex solution and the volume was completed to $2 \mathrm{~mL}$ with toluene or isooctane. The final concentration $\mathrm{C}_{\mathrm{Ag}}{ }^{+}$of silver precursors was equal to $0.825 \mathrm{mmol} \mathrm{L}^{-1}$ but could also be changed and multiplied by 2 or 4 for a fixed concentration of $\mathrm{Au}$ seed $\left(\mathrm{C}_{\text {seed }}=\right.$ $\left.1.4 \mu \mathrm{mol} \mathrm{L}{ }^{-1}\right)$. Furthermore, the final concentration of Au seeds could be also tuned from $\mathrm{C}_{\text {seed }}$ to $\mathrm{C}_{\text {seed }} / 2$ or $\mathrm{C}_{\text {seed }} / 4$ (See SI for the calculation of the concentrations and Table 1). The silver shell overgrowth took place under annealing at $90^{\circ} \mathrm{C}$ for 5 hours for dodecanethiol functionalized AuNPs and 2 hours for oleylamine functionalized AuNPs. A slightly lower temperature of $80^{\circ} \mathrm{C}$ was also used for $5 \mathrm{~nm}$ dodecanethiol functionalized single crystalline AuNPs. The NPs were finally washed with $1 \mathrm{~mL}$ of acetone and dispersed in chloroform.

\subsection{Structural characterization}


4.4.1 Transmission electron microscopy (TEM) images of Au seeds and Au@Ag NPs were acquired with a JEOL $1011(100 \mathrm{kV})$ instrument. High resolution TEM (HRTEM) observations and chemical analyses were performed using a JEOL JEM-2011 UHR operating at $200 \mathrm{kV}$ and fitted with an energy-dispersive X-ray spectroscopy (EDS) microanalyser (PGT-IMIX PC). The samples were prepared by depositing a $20 \mathrm{~mL}$ drop of NP solution on a carbon-coated copper grid. The size distribution of the nanoparticles was determined by measuring around 500 NPs diameters with Image $\mathbf{J}$ software on a minimum of five TEM images at a magnification of 80,000 .

4.4.2 Scanning TEM (STEM) images were taken using a high-angle annular dark field (HAADF) detector in a Nion Ultrastem 200 Cs-corrected microscope operating at $100 \mathrm{kV}$ with a probe size of about $0.07 \mathrm{~nm}$. The probe convergence and HAADF detector minimum collection semi-angles were 35 and 75 mrad respectively, meaning that HAADF images were dominated by Z-contrast, although some diffraction contrast is possible. Elemental maps were obtained using electron energy-loss spectroscopy (EELS) in the spectrum-image (SI) collection mode using the Ag M- and Au M-edges. More detail and typical spectra are included in the supplementary information (see figure S7 in supporting information).

4.4.3 Scanning electron microscopy (SEM) images associated with energy dispersive spectroscopy (EDS) on the nanoparticles 3D superlattices were performed with a JEOL5510LV. The samples were prepared by depositing several drops of colloidal solution onto a silicon wafer.

\subsection{IR and $U V$-Vis spectroscopies}

Infrared (IR) spectra of oleylamine, $\mathrm{Au}$ - and Ag-oleylamine complexes were recorded using an ATR diamond crystal accessory on a Bruker Equinox 55 spectrometer equipped with a $\mathrm{Ge} / \mathrm{KBr}$ beamsplitter and a liquid nitrogen-cooled MCT detector. The extinction spectrum of NP solutions with a fixed concentration of $0.14 \mu \mathrm{mol} \mathrm{L}^{-1}$ was measured at room temperature with a UV-vis-NIR spectrophotometer between 300 and $700 \mathrm{~nm}$ using a quartz cell $(\mathrm{L}=1$ $\mathrm{mm})$. All the $\mathrm{Au}(\mathrm{PC})$ and $\mathrm{Au}(\mathrm{PC}) @ \mathrm{Ag}$ NPs were dispersed in toluene.

\subsection{Discrete dipole approximation (DDA) simulations}

All the calculations of the extinction spectra performed in this work were carried out using the discrete dipole approximation (DDA) method. This method is based on the theory originally developed by Purcell and Pennypacker for the study of interstellar dust grains [67]. Subsequent improvements have enabled its use for calculating the extinction, absorption and 
scattering cross sections of other fine particles [68-70]. Due to its versatility this method has been widely used in the last few years to simulate the optical response of various metallic systems composed of either individual or multiple objects of any size and shape[71-76]. Here, the extinction spectra of $\mathrm{Au}(\mathrm{PC})$ and $\mathrm{Au}(\mathrm{PC}) @ \mathrm{Ag} \mathrm{NPs}$ were calculated using the free software DDSCAT 7.3 written by Draine and Flatau [77]. Size-corrected dielectric functions were calculated using the procedures described elsewhere for the spherical core $[78,79]$ and the shell geometries [80]. This correction aims to account for the reduction of the effective electron mean free path $L_{\text {eff }}$ due to the scattering of the conduction electrons from the particle surface as well as the core-shell interface. The aforementioned size correction was performed on the dielectric functions of bulk $\mathrm{Au}$ and $\mathrm{Ag}$ taken from Palik's handbook [81]. Further information on the calculation of the size-corrected dielectric functions are given in supporting information and their graphs are presented in figures S8-S10 in supporting information.

\subsection{Low-frequency Raman spectroscopy (LFRS)}

Samples for LFRS measurements were prepared by depositing several drops of colloidal solution onto a silicon wafer. The spectra were recorded with a six-pass tandem Fabry-Perot interferometer coupled with an $\mathrm{Si}$ avalanche photodiode for the detection of the scattered light. Because of the weak signal from the samples an acquisition time of several hours was required for each spectrum to obtain a sufficient signal-to-noise ratio. The $647.1 \mathrm{~nm}$ line of a $\mathrm{Kr}^{+}$laser was used as excitation source. To prevent damage of the sample during the long irradiation time, the laser beam was focused on the sample surface at a low optical intensity of about $10^{10} \mathrm{~W} \mathrm{~m}^{-2}$. This system allows us to record inelastic light scattering spectra with low frequency shifts $(v<300 \mathrm{GHz})$. To facilitate and support our interpretation of the LFRS spectra, the measured frequencies were compared with analytical calculations based on Lamb theory [53].

\section{Acknowledgements}

The authors gratefully thank Mr. David Montero (Institut des Matériaux de Paris Centre, FR2482) and Dr. Anh-Tu Ngo for SEM imaging. They also acknowledge financial support from the French "METSA" network (FR CNRS 3507) and from the European Union's 
ESTEEEM3 project (Grant Agreement No. 823717). L.S. acknowledges support from the Bourgogne Franche-Comté Graduate School EUR-EIPHI (ANR-17-EURE-0002).

\section{References}

[1] Liu X, Wang D and Li Y 2012 Synthesis and catalytic properties of bimetallic nanomaterials with various architectures Nano Today $7448-66$

[2] Guo S and Wang E 2011 Noble metal nanomaterials: Controllable synthesis and application in fuel cells and analytical sensors Nano Today 6 240-64

[3] Zaleska-Medynska A, Marchelek M, Diak M and Grabowska E 2016 Noble metal-based bimetallic nanoparticles: the effect of the structure on the optical, catalytic and photocatalytic properties Adv. Colloid Interface Sci. 229 80-107

[4] Hammer B and Norskov J K 1995 Why gold is the noblest of all the metals Nature 376 23840

[5] Lee K-S and El-Sayed M A 2006 Gold and Silver Nanoparticles in Sensing and Imaging: Sensitivity of Plasmon Response to Size, Shape, and Metal Composition J. Phys. Chem. B 11019220 5

[6] Jain P K, Huang X, El-Sayed I H and El-Sayed M A 2008 Noble Metals on the Nanoscale: Optical and Photothermal Properties and Some Applications in Imaging, Sensing, Biology, and Medicine Acc. Chem. Res. 41 1578-86

[7] Roduner E 2006 Size matters: why nanomaterials are different Chem. Soc. Rev. 35583

[8] Cortie M B and McDonagh A M 2011 Synthesis and Optical Properties of Hybrid and Alloy Plasmonic Nanoparticles Chem. Rev. 111 3713-35

[9] Wu W, Njoki P N, Han H, Zhao H, Schiff E A, Lutz P S, Solomon L, Matthews S and Maye M M 2011 Processing Core/Alloy/Shell Nanoparticles: Tunable Optical Properties and Evidence for Self-Limiting Alloy Growth J. Phys. Chem. C $1159933-42$

[10] Samal A K, Polavarapu L, Rodal-Cedeira S, Liz-Marzán L M, Pérez-Juste J and PastorizaSantos I 2013 Size Tunable Au@Ag Core-Shell Nanoparticles: Synthesis and Surface-Enhanced Raman Scattering Properties Langmuir 29 15076-82

[11] Zhou N, López-Puente V, Wang Q, Polavarapu L, Pastoriza-Santos I and Xu Q-H 2015 Plasmon-enhanced light harvesting: applications in enhanced photocatalysis, photodynamic therapy and photovoltaics RSC Adv. 5 29076-97

[12] Mao K, Zhou Z, Han S, Zhou X, Hu J, Li X and Yang Z 2018 A novel biosensor based on $\mathrm{Au} @ \mathrm{Ag}$ core-shell nanoparticles for sensitive detection of methylamphetamine with surface enhanced Raman scattering Talanta 190 263-8

[13] Sytwu K, Vadai M and Dionne J A 2019 Bimetallic nanostructures: combining plasmonic and 
catalytic metals for photocatalysis Adv. Phys. X 41619480

[14] Radhu S 2020 Photocatalytic degradation of textile dye molecules by Ag@ Au core-shell nanoparticles Mater. Today Proc. S2214785320305186

[15] Zhang Y-W 2018 Bimetallic nanostructures shape-controlled synthesis for catalysis, plasmonics, and sensing applications (Beijing: Wiley)

[16] School of Materials and Energy, Guangdong University of Technology, Guangzhou, 510006, P. R. China. and Li N 2018 Au@ Ag Core-shell Nanoparticles Supported on Carbon Nanotubes as Promising Catalysts for Oxygen Electroreduction Int. J. Electrochem. Sci. 6756-70

[17] Lu L, Burkey G, Halaciuga I and Goia D V 2013 Core-shell gold/silver nanoparticles: Synthesis and optical properties J. Colloid Interface Sci. 392 90-5

[18] Ma Y, Li W, Cho E C, Li Z, Yu T, Zeng J, Xie Z and Xia Y 2010 Au@Ag Core-Shell Nanocubes with Finely Tuned and Well-Controlled Sizes, Shell Thicknesses, and Optical Properties ACS Nano 4 6725-34

[19] Gilroy K D, Ruditskiy A, Peng H-C, Qin D and Xia Y 2016 Bimetallic Nanocrystals: Syntheses, Properties, and Applications Chem. Rev. 116 10414-72

[20] Haidar I, Day A, Decorse P, Lau-Truong S, Chevillot-Biraud A, Aubard J, Félidj N and Boubekeur-Lecaque L 2019 Tailoring the Shape of Anisotropic Core-Shell Au-Ag Nanoparticles in Dimethyl Sulfoxide Chem. Mater. 31 2741-9

[21] Dai L, Song L, Huang Y, Zhang L, Lu X, Zhang J and Chen T 2017 Bimetallic Au/Ag CoreShell Superstructures with Tunable Surface Plasmon Resonance in the Near-Infrared Region and High Performance Surface-Enhanced Raman Scattering Langmuir 33 5378-84

[22] Nasrabadi H T, Abbasi E, Davaran S, Kouhi M and Akbarzadeh A 2016 Bimetallic nanoparticles: Preparation, properties, and biomedical applications Artif. Cells Nanomedicine Biotechnol. 44 376-80

[23] Wu Y, Jiang P, Jiang M, Wang T-W, Guo C-F, Xie S-S and Wang Z-L 2009 The shape evolution of gold seeds and gold@silver core-shell nanostructures Nanotechnology 20305602

[24] Tsuji M, Miyamae N, Lim S, Kimura K, Zhang X, Hikino S and Nishio M 2006 Crystal Structures and Growth Mechanisms of Au@Ag Core-Shell Nanoparticles Prepared by the Microwave-Polyol Method Cryst. Growth Des. 6 1801-7

[25] Tsuji M, Matsuo R, Jiang P, Miyamae N, Ueyama D, Nishio M, Hikino S, Kumagae H, Kamarudin K S N and Tang X-L 2008 Shape-Dependent Evolution of Au@Ag Core-Shell Nanocrystals by PVP-Assisted N,N -Dimethylformamide Reduction Cryst. Growth Des. 8 2528-36

[26] Ji Y, Yang S, Guo S, Song X, Ding B and Yang Z 2010 Bimetallic Ag/Au nanoparticles: A low temperature ripening strategy in aqueous solution Colloids Surf. Physicochem. Eng. Asp. 372 204-9

[27] Xia Y, Gilroy K D, Peng H-C and Xia X 2017 Seed-Mediated Growth of Colloidal Metal Nanocrystals Angew. Chem. Int. Ed. 56 60-95 
[28] Fan F-R, Liu D-Y, Wu Y-F, Duan S, Xie Z-X, Jiang Z-Y and Tian Z-Q 2008 Epitaxial Growth of Heterogeneous Metal Nanocrystals: From Gold Nano-octahedra to Palladium and Silver Nanocubes J. Am. Chem. Soc. 130 6949-51

[29] Liu Y, Zhou J, Wang B, Jiang T, Ho H-P, Petti L and Mormile P 2015 Au@ Ag core-shell nanocubes: epitaxial growth synthesis and surface-enhanced Raman scattering performance Phys. Chem. Chem. Phys. 17 6819-26

[30] Loza K, Heggen M and Epple M 2020 Synthesis, Structure, Properties, and Applications of Bimetallic Nanoparticles of Noble Metals Adv. Funct. Mater. 1909260

[31] Gawande M B, Goswami A, Asefa T, Guo H, Biradar A V, Peng D-L, Zboril R and Varma R S 2015 Core-shell nanoparticles: synthesis and applications in catalysis and electrocatalysis Chem. Soc. Rev. 44 7540-90

[32] Chapus L, Aubertin P, Joiret S, Lucas I T, Maisonhaute E and Courty A 2017 Tunable SERS Platforms from Small Nanoparticle 3D Superlattices: A Comparison between Gold, Silver, and Copper ChemPhysChem 18 3066-75

[33] Ko F-H, Tai M, Liu F-K and Chang Y-C 2015 Au-Ag core-shell nanoparticles with controllable shell thicknesses for the detection of adenosine by surface enhanced Raman scattering Sens. Actuators B Chem. $211283-9$

[34] Peng S, McMahon J M, Schatz G C, Gray S K and Sun Y 2010 Reversing the sizedependence of surface plasmon resonances Proc. Natl. Acad. Sci. 107 14530-4

[35] Srnová-Šloufová I, Lednický F, Gemperle A and Gemperlová J 2000 Core-Shell (Ag)Au Bimetallic Nanoparticles: Analysis of Transmission Electron Microscopy Images Langmuir 16 992835

[36] Guisbiers G, Mendoza-Cruz R, Bazán-Díaz L, Velázquez-Salazar J J, Mendoza-Perez R, Robledo-Torres J A, Rodriguez-Lopez J-L, Montejano-Carrizales J M, Whetten R L and JoséYacamán M 2016 Electrum, the Gold-Silver Alloy, from the Bulk Scale to the Nanoscale: Synthesis, Properties, and Segregation Rules ACS Nano 10 188-98

[37] Shore M S, Wang J, Johnston-Peck A C, Oldenburg A L and Tracy J B 2011 Synthesis of $\mathrm{Au}(\mathrm{Core}) / \mathrm{Ag}($ Shell) Nanoparticles and their Conversion to AuAg Alloy Nanoparticles Small 7 230-4

[38] Gao C, Hu Y, Wang M, Chi M and Yin Y 2014 Fully Alloyed Ag/Au Nanospheres: Combining the Plasmonic Property of Ag with the Stability of Au J. Am. Chem. Soc. 136 7474-9

[39] Courty A 2010 Silver Nanocrystals: Self-Organization and Collective Properties J. Phys. Chem. C 114 3719-31

[40] Wang, Luo J, Fan Q, Suzuki M, Suzuki I S, Engelhard M H, Lin Y, Kim N, Wang J Q and Zhong C-J 2005 Monodispersed Core-Shell Fe ${ }_{3} \mathrm{O}_{4} @$ @u Nanoparticles J. Phys. Chem. B 109 21593-601

[41] Hiramatsu H and Osterloh F E 2004 A Simple Large-Scale Synthesis of Nearly Monodisperse Gold and Silver Nanoparticles with Adjustable Sizes and with Exchangeable Surfactants Chem. Mater. $162509-11$ 
[42] Ben Aissa M A, Tremblay B, Andrieux-Ledier A, Maisonhaute E, Raouafi N and Courty A 2015 Copper nanoparticles of well-controlled size and shape: a new advance in synthesis and selforganization Nanoscale 7 3189-95

[43] Portalès H, Goubet N, Sirotkin S, Duval E, Mermet A, Albouy P-A and Pileni M-P 2012 Crystallinity Segregation upon Selective Self-Assembling of Gold Colloidal Single Nanocrystals Nano Lett. 12 5292-8

[44] Goubet N, Richardi J, Albouy P A and Pileni M P 2011 How to Predict the Growth Mechanism of Supracrystals from Gold Nanocrystals J. Phys. Chem. Lett. 2 417-22

[45] Ouhenia-Ouadahi K, Andrieux-Ledier A, Richardi J, Albouy P-A, Beaunier P, Sutter P, Sutter E and Courty A 2016 Tuning the Growth Mode of 3D Silver Nanocrystal Superlattices by Triphenylphosphine Chem. Mater. 28 4380-9

[46] Borges J, Ribeiro J A, Pereira E M, Carreira C A, Pereira C M and Silva F 2011 Preparation and characterization of DNA films using oleylamine modified Au surfaces J. Colloid Interface Sci. $358626-34$

[47] Talapin D V, Lee J-S, Kovalenko M V and Shevchenko E V 2010 Prospects of Colloidal Nanocrystals for Electronic and Optoelectronic Applications Chem. Rev. 110 389-458

[48] Zhang J, Tang Y, Weng L and Ouyang M 2009 Versatile Strategy for Precisely Tailored Core@Shell Nanostructures with Single Shell Layer Accuracy: The Case of Metallic Shell Nano Lett. $94061-5$

[49] Forsythe W E and Smithsonian Institution 2003 Smithsonian physical tables (Norwich, N.Y.: Knovel)

[50] Courty A, Lisiecki I and Pileni M P 2002 Vibration of self-organized silver nanocrystals $J$. Chem. Phys. 116 8074-8

[51] Lamb H 1881 On the Vibrations of an Elastic Sphere Proc. Lond. Math. Soc. 189-212

[52] Eringen A C and Suhubi E S 1975 Elastodynamics. 1: Finite motions (New York: Acad. Pr)

[53] Portalès H, Saviot L, Duval E, Gaudry M, Cottancin E, Pellarin M, Lermé J and Broyer M 2002 Resonant Raman scattering by quadrupolar vibrations of Ni-Ag core-shell nanoparticles Phys. Rev. B 65165422

[54] Portalès H, Goubet N, Saviot L, Yang P, Sirotkin S, Duval E, Mermet A and Pileni M-P 2010 Crystallinity Dependence of the Plasmon Resonant Raman Scattering by Anisotropic Gold Nanocrystals ACS Nano 4 3489-97

[55] Portales H, Goubet N, Saviot L, Adichtchev S, Murray D B, Mermet A, Duval E and Pileni M-P 2008 Probing atomic ordering and multiple twinning in metal nanocrystals through their vibrations Proc. Natl. Acad. Sci. 105 14784-9

[56] Neighbours J R and Alers G A 1958 Elastic Constants of Silver and Gold Phys. Rev. 111 $707-12$

[57] Yaseen T, Pu H and Sun D-W 2019 Fabrication of silver-coated gold nanoparticles to 
simultaneously detect multi-class insecticide residues in peach with SERS technique Talanta 196537 45

[58] Wang K, Sun D-W, Pu H and Wei Q 2019 Surface-enhanced Raman scattering of core-shell $\mathrm{Au} @ \mathrm{Ag}$ nanoparticles aggregates for rapid detection of difenoconazole in grapes Talanta 191 449-56

[59] Zheng N, Fan J and Stucky G D 2006 One-Step One-Phase Synthesis of Monodisperse Noble-Metallic Nanoparticles and Their Colloidal Crystals J. Am. Chem. Soc. 128 6550-1

[60] Andrieux-Ledier A, Tremblay B and Courty A 2013 Stability of Self-Ordered Thiol-Coated Silver Nanoparticles: Oxidative Environment Effects Langmuir 29 13140-5

[61] Goubet N, Yan C, Polli D, Portalès H, Arfaoui I, Cerullo G and Pileni M-P 2013 Modulating Physical Properties of Isolated and Self-Assembled Nanocrystals through Change in Nanocrystallinity Nano Lett. 13 504-8

[62] Mourdikoudis S and Liz-Marzán L M 2013 Oleylamine in Nanoparticle Synthesis Chem. Mater. 25 1465-76

[63] Shen C, Hui C, Yang T, Xiao C, Tian J, Bao L, Chen S, Ding H and Gao H 2008 Monodisperse Noble-Metal Nanoparticles and Their Surface Enhanced Raman Scattering Properties Chem. Mater. 20 6939-44

[64] Lavigne A, Sparfel D, Baranne-Lafont J, Cuong N K and Maumy M 1990 MECHANISM OF PRIMARY ALIPI-IATIC AMINES OXIDATION TO NITRILES BY THE CUPROUS CHLORIDE DIOXYGEN - PYRIDINE SYSTEM. Tetrahedron Letters 313305

[65] Goubet N, Portalès H, Yan C, Arfaoui I, Albouy P-A, Mermet A and Pileni M-P 2012 Simultaneous Growths of Gold Colloidal Crystals J. Am. Chem. Soc. 134 3714-9

[66] Goubet N, Tempra I, Yang J, Soavi G, Polli D, Cerullo G and Pileni M P 2015 Size and nanocrystallinity controlled gold nanocrystals: synthesis, electronic and mechanical properties Nanoscale $73237-46$

[67] Purcell E M and Pennypacker C R 1973 Scattering and Absorption of Light by Nonspherical Dielectric Grains Astrophys. J. 186705

[68] Draine B T and Flatau P J 1994 Discrete-Dipole Approximation For Scattering Calculations J. Opt. Soc. Am. A 111491

[69] Draine B T and Flatau P J 2008 Discrete-dipole approximation for periodic targets: theory and tests J. Opt. Soc. Am. A 252693

[70] Gutkowicz-Krusin D and Draine B T 2012 Propagation of Electromagnetic Waves on a Rectangular Lattice of Polarizable Points Opt. Express 201247

[71] Yang W, Schatz G C and Van Duyne R P 1995 Discrete dipole approximation for calculating extinction and Raman intensities for small particles with arbitrary shapes J. Chem. Phys. 103 869-75

[72] Wei J J, Yang P, Portalès H, Albouy P-A and Pileni M P 2016 Collective Surface Plasmon Resonances in Two-Dimensional Assemblies of Au and Ag Nanocrystals: Experiments and Discrete Dipole Approximation Simulation J. Phys. Chem. C 120 13732-8 
[73] Sosa I O, Noguez C and Barrera R G 2003 Optical Properties of Metal Nanoparticles with Arbitrary Shapes J. Phys. Chem. B 107 6269-75

[74] Brioude A and Pileni M P 2005 Silver Nanodisks: Optical Properties Study Using the Discrete Dipole Approximation Method J. Phys. Chem. B 109 23371-7

[75] Shuford K L, Ratner M A and Schatz G C 2005 Multipolar excitation in triangular nanoprisms J. Chem. Phys. 123114713

[76] Yang P, Portalès H and Pileni M-P 2011 Dependence of the localized surface plasmon resonance of noble metal quasispherical nanoparticles on their crystallinity-related morphologies $J$. Chem. Phys. 134024507

[77] Draine B T and Flatau P J 2013 User Guide for the Discrete Dipole Approximation Code DDSCAT 7.3 ArXiv13056497 Astro-Ph Physicscond-Mat Physicsphysics

[78] Hövel H, Fritz S, Hilger A, Kreibig U and Vollmer M 1993 Width of cluster plasmon resonances: Bulk dielectric functions and chemical interface damping Phys. Rev. B 48 18178-88

[79] Coronado E A and Schatz G C 2003 Surface plasmon broadening for arbitrary shape nanoparticles: A geometrical probability approach J. Chem. Phys. 119 3926-34

[80] Moroz A 2008 Electron Mean Free Path in a Spherical Shell Geometry J. Phys. Chem. C 112 $10641-52$

[81] Palik E D 2004 Handbook of optical constants of solids (Boston: Acad. Press) 